\title{
Barth syndrome cardiomyopathy: targeting the mitochondria with elamipretide
}

\author{
Hani N. Sabbah ${ }^{1}$ \\ Accepted: 21 September 2020 / Published online: 1 October 2020 \\ (C) The Author(s) 2020
}

\begin{abstract}
Barth syndrome (BTHS) is a rare, X-linked recessive, infantile-onset debilitating disorder characterized by early-onset cardiomyopathy, skeletal muscle myopathy, growth delay, and neutropenia, with a worldwide incidence of 1/300,000-400,000 live births. The high mortality rate throughout infancy in BTHS patients is related primarily to progressive cardiomyopathy and a weakened immune system. BTHS is caused by defects in the TAZ gene that encodes tafazzin, a transacylase responsible for the remodeling and maturation of the mitochondrial phospholipid cardiolipin (CL), which is critical to normal mitochondrial structure and function (i.e., ATP generation). A deficiency in tafazzin results in up to a $95 \%$ reduction in levels of structurally mature CL. Because the heart is the most metabolically active organ in the body, with the highest mitochondrial content of any tissue, mitochondrial dysfunction plays a key role in the development of heart failure in patients with BTHS. Changes in mitochondrial oxidative phosphorylation reduce the ability of mitochondria to meet the ATP demands of the human heart as well as skeletal muscle, namely ATP synthesis does not match the rate of ATP consumption. The presence of several cardiomyopathic phenotypes have been described in BTHS, including dilated cardiomyopathy, left ventricular noncompaction, either alone or in conjunction with other cardiomyopathic phenotypes, endocardial fibroelastosis, hypertrophic cardiomyopathy, and an apical form of hypertrophic cardiomyopathy, among others, all of which can be directly attributed to the lack of CL synthesis, remodeling, and maturation with subsequent mitochondrial dysfunction. Several mechanisms by which these cardiomyopathic phenotypes exist have been proposed, thereby identifying potential targets for treatment. Dysfunction of the sarcoplasmic reticulum $\mathrm{Ca}^{2+}$-ATPase pump and inflammation potentially triggered by circulating mitochondrial components have been identified. Currently, treatment modalities are aimed at addressing symptomatology of HF in BTHS, but do not address the underlying pathology. One novel therapeutic approach includes elamipretide, which crosses the mitochondrial outer membrane to localize to the inner membrane where it associates with cardiolipin to enhance ATP synthesis in several organs, including the heart. Encouraging clinical results of the use of elamipretide in treating patients with BTHS support the potential use of this drug for management of this rare disease.
\end{abstract}

Keywords Barth syndrome $\cdot$ Mitochondria $\cdot$ Cardiomyopathies $\cdot$ Electron transport chain $\cdot$ Adenosine triphosphate

\section{Introduction}

Barth syndrome (BTHS) is a rare, X-linked recessive disorder characterized by cardiolipin abnormalities, skeletal muscle weakness, abnormal mitochondria, neutropenia, growth retardation, and cardiomyopathy [1]. Current estimates are that the incidence of BTHS is 1/300,000-400,000 live births, with 111

Hani N. Sabbah

hsabbah1@hfhs.org

1 Department of Medicine, Division of Cardiovascular Medicine, Henry Ford Hospital, Henry Ford Health System, 2799 West Grand Boulevard, Detroit, MI 48202, USA diagnosed individuals in the USA and 230-250 worldwide, though it is widely accepted that the disease is underdiagnosed [2]. Biopsies of the heart, liver, and skeletal muscle of patients with BTHS showed both mitochondrial malformations and dysfunction. BTHS patients have a high mortality rate throughout infancy that is primarily related to progressive cardiomyopathy and a weakened immune system [2].

BTHS was first described in 1983 [3]. Identification of the underlying genetic culprit in 1996 [4-7] led to identification of a large number of affected patients [1]. BTHS is caused by mutations in a recessive, $\mathrm{X}$-linked gene located in the distal region of chromosome Xq28. This gene encodes the tafazzin enzyme, a transacylase involved in cardiolipin side chain remodeling. Tafazzin is critical for the maturation of cardiolipin, 
an essential phospholipid of the inner mitochondrial membrane. In BTHS, the significant loss of mature cardiolipin leads to profound derangement in mitochondrial structure and function. Accordingly, mitochondria are a key therapeutic target in the treatment of BTHS patients. The first of two segments of the discussion that follows will focus on the pathophysiology of BTHS. This includes mechanistic insights into the disease, a description of the myopathic and inflammatory pathologies associated with BTHS, and an overview of current and potential new therapies. The second segment will focus on elamipretide, a novel mitochondria-targeting peptide that is a promising therapeutic agent for BTHS.

\section{Mitochondrial bioenergetics}

Mitochondria are an intracellular double-membraned network that are the "power grids" of eukaryotic cells. Mitochondria are most abundant in cells with high energy demands, notably striated muscles. The heart is the most metabolically active organ in the body and possesses the highest content of mitochondria of any tissue [9], comprising about $25 \%$ of cell volume in the human myocardium $[10,11]$ and approximately $35 \%$ of cardiomyocyte volume [12]. The key role of mitochondria in muscle cells is the regeneration of adenosine triphosphate (ATP) from adenosine diphosphate (ADP) using macromolecular complexes that form the electron transport chain (ETC). These protein complexes are imbedded in the mitochondrial inner membrane, and include the following: nicotinamide-adenine dinuculeotide (NADH) dehydrogenase (complex I), succinate dehydrogenase (complex II), cytochrome $\mathrm{bc}_{1}$ (complex III), and cytochrome c oxidase (complex IV) [12]. As electrons flow energetically "down-hill" through the ETC (ultimately reducing oxygen to water), protons are pumped from the matrix into the cristae lumen. This establishes an electrochemical proton gradient characterized by a highly negative mitochondrial membrane potential. The re-entry of protons into the matrix through the ATP synthase (complex V) provides the energy to regenerate ATP from inorganic phosphate (Pi) and ADP (Fig. 1) [13-15]. The coupling of substrate oxidation and ATP formation in the mitochondria, termed oxidative phosphorylation, is central to tissue and organ health [12]. Cardiolipin is a unique phospholipid expressed almost exclusively in the inner mitochondrial membrane and involved in nearly every aspect of mitochondrial structure and function.

Humans produce and consume about $65 \mathrm{~kg}$ of ATP every day, with the heart accounting for about $8 \%$ of ATP consumption daily, or about $6 \mathrm{~kg}$ [16]. About $90 \%$ of cellular ATP within the myocardium is used to meet the enormous energy requirements for contraction and relaxation, both of which are ATP-dependent [17]. Mitochondrial dysfunction therefore plays a central role in a wide variety of metabolic and cardiac disorders, including heart failure (HF) and BTHS [1, 18], the subject of this review. Dysfunctional mitochondria in skeletal muscle has been implicated in HF-associated exercise intolerance [19] and in skeletal muscle myopathy and exercise intolerance in BTHS [20].

Because ATP cannot be stored, it is critical that the rate of ATP synthesis matches the rate of ATP consumption [8]. This process is accomplished by mitochondrial oxidative phosphorylation within the ETC using fatty acids as the primary fuel source [21]. Although there are numerous reasons why human hearts fail, a mismatch between ATP supply and demand has been observed in almost all etiologies of HF [16]. Changes in oxidative phosphorylation are characterized by decreased energy production, with reductions in oxygen utilization, and respiratory chain and ATP synthase activity. Mitochondrial dysfunction also contributes to skeletal muscle performance limitations by reducing the ability of mitochondria to meet the ATP demands of aerobic, slow-twitch, fatigue-resistant working muscles [22]. Lack of availability of energy during activity leads, in part, to exercise intolerance, a characteristic feature of both acquired forms of HF and BTHS [23].

\section{Tafazzin, TAZ gene mutations, and Barth syndrome}

The TAZ gene provides instructions for producing the enzyme tafazzin. Since tafazzin transacylase activity is responsible for cardiolipin remodeling, it is critical to maintaining mitochondrial inner membrane structure and function. Tafazzin is encoded by the TAZ gene, is highly expressed in cardiac and skeletal muscle, and functions as a phospholipidlysophospholipid transacylase in humans [6, 7]. The protein is produced by alternate splicing of the TAZ gene or G4.5. The gene is a single-copy gene composed of $\sim 11 \mathrm{~kb}$ of genomic DNA with 11 exons, which maps to Xq28, and two ATG initiation sites. Multiple mRNAs can be produced by alternate splicing at exons $5-7$, resulting in tafazzin proteins ranging from 129 to 292 amino acids in length that differ at the N-terminal and central regions. Two putative functional domains have been identified: (1) a highly hydrophobic segment of 30 residues at the N-terminus, which acts as a membrane anchor, and (2) a hydrophilic segment in the central region that forms an exposed loop interacting with other proteins.

As alluded to earlier, tafazzin is a nuclear-encoded acyltransferase that is "trafficked" to the inner mitochondrial membrane and functions in remodeling cardiolipin fatty acyl chains [24]. The putative phospholipid-binding site, which is the active site of tafazzin, is a 57-amino acid cleft with two open ends and positively charged residues [25]. Tafazzin has at least 4 different isoforms and has a molecular weight of 
Fig. 1 Depiction of mitochondrial inner membrane and electron transport chain consisting of complexes I through V. Reactive oxygen species (ROS) are generated at complexes I and III. Excessive ROS production can lead to mitochondrial and cardiomyocyte dysfunction by inhibiting the tricarboxylic acid (TCA) cycle enzymes and adenosine triphosphate (ATP) synthase, and by damaging mtDNA. Adapted with permission from reference 8 . CK, creatine kinase; CoQ10, coenzyme Q10; Cyt $\mathrm{C}$, cytochrome c; mtDNA, mitochondrial DNA; Pi, inorganic phosphate

\section{INNER MITOCHONDRIAL MEMBRANE (Cardiolipin)}

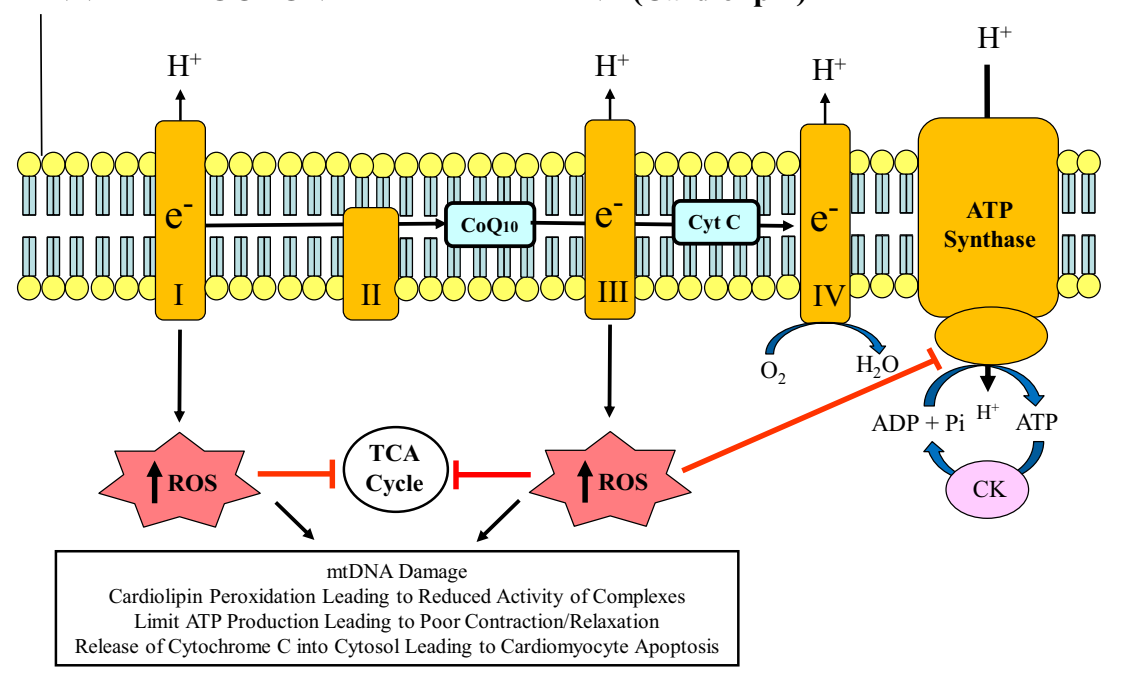

approximately $35 \mathrm{kDa}$, but may also appear in lower molecular weights due to species differences in isoform expression $[4,5]$. The TAZ gene contains two peptides independent of its active site for directing the protein to the mitochondria, forming residues 84-95 in exon 3 and residues 185-200 in exon 7/8 [26]. Within the mitochondria, tafazzin localizes between the inner mitochondrial membrane and outer mitochondrial membrane, facing the intermembrane space $[27,28]$. Tafazzin's characteristic interfacial anchoring is achieved by its hydrophobic sequence from residues 215 232 [29]. Finally, the translocase of the outer membrane and the translocase of the inner membrane mediate tafazzin's movement and insertion into the outer mitochondrial membrane and anchoring to the inner mitochondrial membrane [29].

Mutations in the TAZ gene have been associated with mitochondrial dysfunction in BTHS cardiomyopathies, dilated cardiomyopathy, hypertrophic-dilated cardiomyopathy, endocardial fibroelastosis, LV noncompaction, breast cancer, papillary thyroid carcinoma, non-small cell lung cancer, glioma, gastric cancer, thyroid neoplasms, and rectal cancer [30-32]. Several functional classes of TAZ gene mutations have been classified based on the pathogenic loss-offunction mechanisms of each mutation. A variety of TAZ gene mutations, including splice site mutations, insertions, deletions, nonsense, and missense mutations, located throughout the $T A Z$ gene have been reported to cause BTHS. Individuals harboring mutations in the TAZ gene, namely patients with BTHS, manifest compromised or missing tafazzin enzymatic activity, resulting in specific alterations in cardiolipin that include increased molecular species heterogeneity, decreased levels of cardiolipin, and increased levels of monolysocardiolipin. If, for example, a given TAZ gene mutation gives rise to a tafazzin protein with residual enzyme activity, lesser changes in cardiolipin content and composition, and a milder phenotype, may be anticipated [33]. On the other hand, more severe mutations in the TAZ gene that lead to complete loss of transacylase activity will have a more deleterious effect on inner mitochondrial membrane structure and function. Despite this, TAZ gene mutations have been described in which the correlation between genotype and phenotype is not apparent [34]. Conceivably, individual differences in TAZ mRNA splicing and mRNA stability or differences in tafazzin protein turnover rate could affect residual enzyme activity. Similarly, one or more extraneous phenotypic modifiers, ranging from environmental to biochemical, could be responsible for differences in the degree of disease manifestation [33, 34]. Despite the X-linked inheritance of Barth's syndrome and the identification of many females carrying $T A Z$ gene mutations, there are no reports of females with the classic pathology observed in BTHS.

\section{Cardiolipin and Barth syndrome}

Among mitochondrial lipids, cardiolipin is unique. It is the only phospholipid that is specific to mitochondria. Cardiolipin accounts for roughly $20 \%$ of inner membrane phospholipids, and plays a vital role in the molecular organization and physiological function of mitochondria. Cardiolipin is very abundant in mitochondria of myocytes of the heart and skeletal muscle. Unlike other glycerophospholipids, cardiolipin is unique in that two phosphatidate moieties share the same glycerol head group, giving rise to an anionic phospholipid with four esterified fatty acyl chains and a cone-shaped structure [35]. In myocytes and all other eukaryotes, cardiolipin is confined to the inner mitochondrial membrane. In cardiomyocytes and skeletal muscle, nearly $90 \%$ of cardiolipin exists as a single molecular species, tetralinoleoylcardiolipin [36]. Formation of 
tetralinoleoylcardiolipin depends largely on a series of phospholipid remodeling reactions, with tafazzin being one of the last transacylases leading to mature cardiolipin [37]. In addition to tafazzin, cardiolipin remodeling can occur via the endoplasmic reticulum localized enzyme acyl-CoA:lysocardiolipin acyltransferase (ALCAT1) [38, 39] and via mitochondrial monolysocardiolipin acyltransferase (MLCAT) [40, 41]. Even though the relative contribution of ALCAT1 and MLCAT to the total pool of mature cardiolipin is not known, it is well recognized that ALCAT1- and MLCAT-mediated reactions cannot fully compensate for loss of tafazzin [35]. Tafazzin catalyzes remodeling of immature cardiolipin to its mature composition containing a predominance of tetralinoleoyl moieties. The condensation of phosphatidylglycerol and CDP-diacylglycerol produces immature cardiolipin which contains predominantly shorter chain saturated and monounsaturated fatty acyl chains (palmitic and oleic acids). The immature cardiolipin is then remodeled to form mature cardiolipin through the coordinated activity of specific lipases and acyltransferase/transacylase, primarily tafazzin [42-44]. Mature cardiolipin is responsible for maintenance of mitochondrial membrane fluidity, osmotic stability, and proper curvature of the cristae, which serves as a crucial binding site for electron transport chain (ETC) proteins and stabilization of the ETC supercomplexes [6, 45-47].

Cardiolipin plays essential roles in mitochondrial protein/ metabolite transport, mitochondrial morphology, and mitochondrial bioenergetics [1]. Nuclear-encoded mitochondrial proteins are transported into mitochondria after translation in the cytosol. Protein transport across mitochondrial membranes is mediated by specialized translocases that are located in cardiolipin-rich contact sites where the inner and outer membranes converge to close proximity [1, 48, 49]. Mitochondrial morphology is markedly abnormal when cardiolipin is deficient, as in BTHS, where marked malformation of cristae structures is evident $[1,50]$. Similar abnormalities of mitochondrial morphology have been reported in many tafazzin-deficient cell and animal models [1].

Cardiolipin regulates several enzyme activities and, in particular, those related to oxidative phosphorylation and coupled respiration [51-56]. Cardiolipin binds complexes I, III, IV, and $\mathrm{V}$ and stabilizes the super complexes (I/III/IV and II/III/ IV), indicating an absolute requirement of cardiolipin for catalytic activity of these complexes [52, 53, 57, 58]. The activity of numerous respiratory chain complexes is directly related to cardiolipin content $[54,59,60]$ and composition $[55,56,61]$. Under normal physiological conditions, monolysocardiolipin is converted to mature cardiolipin by a functional tafazzin enzyme. Impaired tafazzin activity in BTHS leads to the accumulation of monolysocardiolipin and an overall loss in cardiolipin species. Both of these contribute to morphological abnormalities of the mitochondrial inner membrane and inefficient cellular bioenergetics [62-66].

\section{Cardiomyopathies of Barth syndrome}

Cardiac disease is common in Barth syndrome and is often diagnosed within the first year of life. In fact, cardiomyopathy is the single most frequent sign, occurring in approximately $90 \%$ of males with BTHS, although the manifestation and severity vary for each individual. Several cardiomyopathic phenotypes have been described. Dilated cardiomyopathy is common and is characterized by decreased left ventricular (LV) systolic function, increased LV mass, and an increased LV end-diastolic dimension [23, 67, 68]. Left ventricular noncompaction is also commonly seen either alone or in conjunction with other cardiomyopathic phenotypes and is characterized by LV trabeculations with associated wall motion abnormalities [68]. Endocardial fibroelastosis may be seen, although less commonly [69]. Hypertrophic cardiomyopathy [70], as well as an apical form of hypertrophyic cardiomyopathy [71], is also reported to occur in BTHS. A mixed hypertrophic-dilated cardiac phenotype characterized by thickening of the LV walls with an increase in LV mass and end-diastolic dimension, and depressed systolic function has also been reported [72]. Transition between distinct phenotypes has also been described in the setting of LV noncompaction termed "undulating phenotype" [73]. No current mechanism has been proposed that explains the various cardiomyopathic phenotypes seen in BTHS, yet evidence of varying phenotypic cardiac disease is well documented in families with recognized sarcomeric mutations suggesting shared molecular etiology of different forms of cardiomyopathy [74]. In addition, there is an increased risk of cardiac arrhythmia in BTHS, some of which may be life-threatening. The arrhythmia may be a direct result of abnormal mitochondrial function and/or a function of the associated cardiac phenotype, as ventricular arrhythmias are well reported in dilated cardiomyopathy, LV noncompaction, and hypertrophic cardiomyopathy $[67,75,76]$.

\section{$\mathrm{Ca}^{2+}$-ATPase, LV diastolic function, and Barth syndrome}

The sarcoplasmic reticulum $\mathrm{Ca}^{2+}$-ATPase (SERCA) is a Ptype ATPase which catalyzes the active transport of $\mathrm{Ca}^{2+}$ ions from the cytoplasm into the sarcoplasmic reticulum. In cardiac muscle, the primary isoform is SERCA2a, which is necessary for the proper regulation of muscle contraction and, importantly, muscle relaxation, by ensuring proper $\mathrm{Ca}^{2+}$ uptake into the sarcoplasmic reticulum during diastole and presence of sufficient $\mathrm{Ca}^{2+}$ load in the sarcoplasmic reticulum for systolic contraction. Phospholamban is a 52 -amino acid protein that, in its non-phosphorylated state, binds to and regulates SERCA by decreasing its affinity for $\mathrm{Ca}^{2+}[77,78]$. When phosphorylated at serine 16 and threonine 17 by protein kinase $\mathrm{A}$ and $\mathrm{Ca}^{2+}$ - 
calmodulin-dependent protein kinase II, respectively, phospholamban dissociates from SERCA, thereby restoring its affinity for $\mathrm{Ca}^{2+}$ [78].

In addition to phospholamaban, SERCA can be regulated by reactive oxygen/nitrogen species (ROS/RNS) [79-81]. The SERCA pump is highly susceptible to oxidative and nitrosative post translational modification as they contain vulnerable cysteine, lysine, and tyrosine residues [79-81]. Under conditions of oxidative stress, superoxide and nitric oxide react to form peroxynitrite, which can then adduct to tyrosine resulting in altered SERCA protein structure and function [82]. Interestingly, SERCA dysfunction, SERCA2a tyrosine nitration, increased ROS formation, and phospholamban dysregulation have all been implicated in cardiomyopathy, a key manifestation of Barth syndrome [67, 83-85]. It was previously shown that cardiolipin is markedly decreased in tafazzin knockdown mice, a model of Barth syndrome, leading to mitochondrial dysfunction and elevated ROS and RNS levels [86, 87]. In tafazzin knockdown mice, SERCA activity was impaired and SERCA2a tyrosine nitration increased compared with wild-type mice [88]. SERCA2a tyrosine nitration was negatively correlated with maximal SERCA activity [88]. These abnormalities were likely due to mitochondrial dysfunction and increased oxidative stress [88] and can promote LV diastolic dysfunction and, subsequently, systolic dysfunction. Left ventricular diastolic dysfunction has been shown in mice models of tafazzin knockdown that manifest noncompaction even in the absence of myocardial fibrosis and myocardial hypertrophy and speculated to result from alterations in cardiolipin and abnormal $\mathrm{Ca}^{2+}$ homeostasis [87]. Patients with myocardial noncompaction, typically present with BTHS, almost always exhibit diastolic dysfunction [89]. Left ventricular diastolic dysfunction with preserved systolic function has been demonstrated in the Friend of GATA-2 (FOG-2) null mouse that also develops noncompaction [90]. These findings suggest that SERCA may be a viable therapeutic target for BTHS.

\section{Inflammatory cytokines and Barth syndrome}

Inflammatory cytokines are signaling molecules produced predominantly by $\mathrm{T}$-helper cells and macrophages and are involved in the upregulation of inflammatory reactions [91]. By initiating the inflammatory response, cytokines regulate the host defense against pathogens mediating the innate immune response. Several reports have demonstrated enhanced expression and release of inflammatory cytokines such as tumor necrosis factor alpha (TNF- $\alpha$ ) and interleukin-6 (IL-6) in patients with acquired HF [92-94]. Cytokines and other inflammatory mediators may contribute to the development and progression of systolic HF. This pathogenic role of inflammatory cytokines in chronic HF is supported by various studies in animal models [95-98]. Systemic administration of $\mathrm{TNF}-\alpha$ in concentrations comparable to those found in the circulation of HF patients has been shown to induce a dilated cardiomyopathy-like phenotype in animal models [95], and cardiac-specific overexpression of TNF- $\alpha$ has been found to promote a phenotype mimicking several features of clinical HF such as cardiac hypertrophy, ventricular dilation and fibrosis, and several biochemical and cellular dysfunctions [96]. More recent studies in gene-modified mice have also shown a link between IL-6 and the development of HF [97]. Inflammatory cytokines may modulate myocardial function by a variety of mechanisms including stimulation of hypertrophy and fibrosis through direct effects on cardiomyocytes and fibroblasts, and impairment of myocardial contractile function through direct effects on intracellular calcium transport. Furthermore, inflammation-mediated signal transduction through adrenergic receptors, induction of apoptosis, and stimulation of genes involved in myocardial remodeling [98] can exacerbate pathology. While increased inflammation is a well-known feature of systolic heart failure, this has been less well studied in patients with HF and preserved ejection fraction (HFpEF). Recent studies, however, have shown that patients with overt HFpEF frequently have increased plasma levels of TNF- $\alpha$ and IL-6 [99]. Moreover, IL-6 infusion in rats results in concentric LV hypertrophy, increased collagen volume fraction, and increased myocardial stiffness [100], all characteristic features of HFpEF.

Given that BTHS is characterized by cardiomyopathies, it would not be surprising to expect increased levels of TNF- $\alpha$ and IL- 6 in this disease state. Elevated levels of TNF- $\alpha$ and IL-6 have indeed been reported in BTHS patients, further exacerbating their cardiomyopathy [101]. In addition to the adverse effects of cytokines on the myocardium as eluded to earlier, increased expression of cytokines can have an adverse effect on growth anomalies widely reported in BTHS. There has been growing evidence that inflammatory processes may influence normal muscle development in children [100]. Increased levels of TNF- $\alpha$ have been shown to suppress the AKT/mTOR (mammalian target of rapamycin) pathway, a crucial pathway for regulating skeletal muscle hypertrophy, thereby increasing muscle catabolism [102-104]. Inflammatory cytokines may also antagonize the anabolic effects of insulin-like growth factor (IGF), a known promoter of muscle hypertrophy [105-107]. It is plausible that an active inflammatory process can contribute to the growth abnormalities and pathology observed in BTHS. Higher levels of IL-6 and lower IGF-1 levels were observed in Barth syndrome patients compared with age-matched controls [101]. This finding may implicate inflammatory processes in the catabolic nature of BTHS pathology, as well as provide a link to mitochondrial dysfunction. Furthermore, lower levels of IGF-1 may contribute to some of the growth delays and myopathies observed in Barth syndrome [101]. 


\section{Cytokines and mitochondrial damage-associated mo- lecular patterns}

Functional, ultrastructural, and dynamic abnormalities of mitochondria occur in BTHS and can lead to cellular stress and death. In recent years, much has been unraveled about the proinflammatory properties of various mitochondrial molecules once released from the mitochondrial compartment and into the cytosol or the extracellular space [108, 109]. Mitochondria can generate and release multiple molecules that can stimulate the innate immune system. On entering the cytoplasm or the extracellular space, mitochondrial damage-associated molecular patterns (DAMPs; also known as mitochondrial alarmins) can become pro-inflammatory and initiate innate and adaptive immune responses by activating cell surface and intracellular receptors $[108,109]$. Among the molecules listed as mitochondrial DAMPs are $N$-formyl peptides, cardiolipin, and mitochondrial DNA (mtDNA), which are released from damaged mitochondria and can activate sterile inflammation [109-112]. Inflammatory responses induced by sterile stimuli can elicit recruitment of neutrophils and macrophages, production of inflammatory cytokines and chemokines, and induction of T cell-mediated adaptive immune responses [113]. Of note, mtDNA has recently been established as an important DAMP and a possible trigger of various inflammatory or degenerative diseases $[114,115]$. Failure to remove the damaged mitochondria with resulting leak of DAMPs has been proposed as an underlying mechanism in the pathophysiology of HF [8].

\section{Skeletal muscle and Barth syndrome}

Exercise intolerance is a hallmark of most, if not all, cardiomyopathies, including Barth syndrome, making it nearly impossible for individuals with BTHS to perform activities of daily living or pursue an acceptable quality of life [116]. In patients with chronic acquired HF, exercise intolerance has been attributed to skeletal muscle atrophy, a shift from slowtwitch, fatigue-resistant, type 1 (oxidative) to fast-twitch type 2 (glycolytic) muscle fibers and to mitochondrial abnormalities [117]. A decrease in the relative composition of type 1 fibers and an increase in type 2 fibers have been shown in an animal model of HF and were associated with reduced exercise tolerance [118]. Changes in composition of skeletal muscle fiber type have also been described in patients with $\mathrm{HF}$ and were also associated with exercise intolerance [119-121]. These patients also manifest a reduction in myosin heavychain type I [121], an isoform that is more abundant in skeletal muscle type 1 aerobic fibers. The shift in fiber-type composition may be partly due to skeletal muscle mitochondrial abnormalities and the associated reduction of ATP synthesis needed by aerobic type 1 fibers [122]. A reduction in ATP production can lead to an adaptation of slow-twitch type 1 fibers to utilizing glycogen as their energy source and thus shifting fiber-type composition toward a fast-twitch phenotype [117]. Under normal physiologic conditions, ATP production by oxidative phosphorylation in the mitochondria fulfills most of the ATP demands of skeletal muscle at rest and during exercise [22]. Mitochondrial dysfunction, therefore, can contribute to decrements in skeletal muscle performance via loss of mitochondrial capacity to generate ATP, or reduced ability to meet the ATP demands of working skeletal muscle. Abnormalities of skeletal muscle mitochondria have been shown in the skeletal muscle of dogs with experimental HF compared with normal dogs [19] as evidenced by reduction in ADP-stimulated respiration, membrane potential, and complex IV [115]. A variety of alterations specific to skeletal muscle, including muscle atrophy, fiber-type changes, defects in oxidative metabolism, and decreased mitochondrial volume density, have been described in patients with HF [123]. Studies using ${ }^{31} \mathrm{P}$ nuclear magnetic resonance (NMR) spectroscopy clearly demonstrated intrinsic skeletal muscle metabolic abnormalities in patients with chronic acquired HF [124].

Daily functional activities, notably ambulation, require a combination of muscular strength, endurance, and balance. Patients with BTHS present with exercise intolerance that is thought to be due to both cardiac impairment and decreased skeletal muscle oxygen utilization [23]. In patients with BTHS, affected individuals showed signs of multiple skeletal muscle impairments including impaired functional exercise capacity, knee and hip flexor, grip, and extensor strength, and reduced daily activity [125]. In patients with Barth syndrome, ${ }^{31} \mathrm{P}$ nuclear magnetic resonance (NMR) spectroscopy showed a higher resting skeletal muscle phosphocreatine to inorganic phosphate ratio ( $\mathrm{PCr} / \mathrm{Pi}$ ) compared with control subjects, a finding consistent with skeletal muscle containing large fractions of type 2, fast-twitch, glycolytic fibers and a smaller fraction of type 1, slow-twitch, oxidative fibers [126, 127]. This finding suggests that individuals with BTHS rely on glycolytic metabolism to a greater extent than those without BTHS. Barth syndrome patients also have higher respiratory exchange ratios during exercise [23] and a greater glucose rate of disposal during a hyperinsulinemic-euglycemic clamp procedure [128]; both suggestive of higher glycolytic dependence. This higher glycolytic capacity is likely compensatory for an impaired mitochondrial capacity to generate ATP. Skeletal muscle and cardiac bioenergetics, as determined from post-exercise $\mathrm{PCr}$ recovery kinetics using ${ }^{31} \mathrm{P}$-MRS, are markedly impaired in BTHS patients when compared with unaffected, age-matched, sedentary controls and are associated with exercise intolerance [20]. Mitochondrial function in tissues such as myocardium and skeletal muscle is closely integrated with physiological demands below the anaerobic threshold [129, 130]. Mitochondrial respiration has been 
shown to be impaired in BTHS patients [66] possibly due to supercomplex destabilization [131], higher degradation and reduced levels of mitochondrial cardiolipin [132], abnormal mitochondrial morphology $[50,133]$, excessive production of reactive oxygen species, and/or defects in ATP synthase activity [66].

\section{Current therapies for Barth syndrome}

Barth syndrome is often considered a lethal early childhood disease. However, improvements in the management of associated neutropenia/infectious risks, skeletal myopathy, and cardiac disease have resulted in improved survival. This is in large part secondary to the treatment of low circulating neutrophil counts and avoidance of infection, systolic dysfunction, and cardiac arrhythmia [71]. Neutropenia is treated with granulocyte colony-stimulating factor (G-CSF) with reasonable success concomitant with appropriate prophylactic antibiotics if clinically indicated. Growth delay is managed with growth hormone (GH) supplementation when central GH deficiency is documented [71]. Arginine depletion has been implicated as contributing to low growth rates in BTHS patients, resulting in an increased use of arginine supplementation as a putative treatment to improve growth rates $[134,135]$.

Clinically significant arrhythmias can be a major cause of mortality in Barth syndrome. The risk of ventricular arrhythmias is well known and may be precipitated by associated metabolic acidosis or concomitant LV systolic dysfunction [136]. Ventricular arrhythmias in the form of ventricular tachycardia or ventricular fibrillation may result in sudden cardiac death. The use of implantable cardioverter defibrillators has been documented in BTHS, although limited data exist regarding the effectiveness of this therapy [137]. Treatment of associated myocardial dysfunction, however, remains paramount to alleviating symptoms as well as prolonging life in patients with BTHS [71]. Medical and surgical options for dilated cardiomyopathy have increased, but remain sparse for other cardiac phenotypes of Barth syndrome. Angiotensin-converting enzyme inhibitors or angiotensin receptor blockers, potentially in combination with approved beta-adrenergic receptor blockers [71], are commonly used to treat BTHS cardiomyopathy. For those patients with worsening HF, more aggressive therapies may be needed in the form of intravenous agents such as vasodilators or inotropes, left ventricular assist devices, and/or cardiac transplantation [138-140].

In a single-center experience, 4 BTHS patients (average age $\sim 2$ years) underwent orthotopic heart transplantation [141]. At the time of the follow-up report, patients were alive with average age of $\sim 8.6$ years. The patients did not demonstrate an increased rate of rejection compared with the general heart transplant population [141].

\section{Novel experimental therapeutic approaches} for treating Barth syndrome

Developing effective therapies for Barth syndrome continues to be a challenge, especially because of the limited number of patients, extraordinary phenotypic variability, and unpredictable clinical course. Experimental and potentially useful therapies include recombinant adenovirus-associated TAZ gene overexpression, peroxisome proliferator-activated receptor (PPAR) agonist, and antioxidants. Recombinant adenoassociated virus ( $\mathrm{AAAV}$ ) vectors are utilized in gene therapy approaches because gene delivery is essentially a nonpathogenic virus that elicits a minimal immune response and persists for long periods of time as an episome within the nucleus of cells, providing stable gene transfer without disruption of genes, by insertional mutagenesis [142]. In a recent study aimed at developing a clinically relevant gene therapy to restore tafazzin function and treat Barth syndrome, AAVmediated TAZ gene replacement was shown to restore mitochondrial and cardioskeletal function in a Barth syndrome mouse model of TAZ gene knockdown [24]. Due to a central role in energy metabolism and mitochondrial bioenergetics, peroxisome proliferator-activated receptors (PPARs) have been considered potential therapeutic targets to ameliorate cardiac dysfunction induced by tafazzin deficiency. Beneficial effects of activation of the PPAR/PGC1 $\alpha$ axis have been demonstrated in various mitochondrial disorders [143]. The PPAR pan-agonist bezafibrate has been shown to ameliorate cardiomyopathy in a mouse model of Barth syndrome [143]. Dysfunction of mitochondria increases ROS production and contributes to cardiac dysfunction in both acquired HF and BTHS [144]. The mitochondria-targeted antioxidant, mito-Tempo, was shown to prevent cardiac dysfunction induced by tafazzin gene knockdown in cardiac myocytes [144]. The above discussed therapies, while promising, must await confirmation of potential benefit by clinical trials in patients with BTHS.

\section{Elamipretide: potential novel therapy for Barth syndrome}

Elamipretide (also known as SS-31, MTP-131, Bendavia ${ }^{\mathrm{TM}}$ ) is a water-soluble, aromatic-cationic mitochondria-targeting tetrapeptide that readily penetrates and transiently localizes to the inner mitochondrial membrane (7115). Elamipretide crosses the mitochondrial outer membrane and localizes to the inner membrane where it associates with cardiolipin, improving membrane stability and ATP production and reducing pathogenic ROS production. Cardiolipin plays a central role in cristae formation, mitochondrial fusion, mtDNA stability and segregation, and function and organization of the respiratory complexes into supercomplexes for oxidative 
phosphorylation. Elamipretide has been shown to enhance ATP synthesis in multiple organs, including the heart, kidney, neurons, and skeletal muscle [145-149]. High-resolution respirometry of individual electron transport chain complexes in permeabilized ventricular fibers from ischemia-reperfusion rats showed that ischemia-reperfusion-induced decrements in mitochondrial complexes I, II, and IV were significantly alleviated with elamipretide [150]. Furthermore, studies in serial block face scanning electron microscopy used to create highresolution 3-dimentional reconstructions of cristae ultrastructure showed that disease-induced fragmentation of cristae networks was improved with elamipretide [150]. Studies using biomimetic membranes modeling the inner mitochondrial membranes also showed that elamipretide improved membrane biophysical properties by aggregating cardiolipin. These studies suggest that mitochondrial structure-function are interdependent and demonstrate that elamipretide targets mitochondrial membranes to sustain cristae networks and improve bioenergetic function [150]. While there are limited data sets with elamipretide in non-clinical BTHS models, it has been studied extensively in models of experimental LV dysfunction and failure. It is these studies in animal models of acquired HF that provide much of the knowledge base available to date that supports the potential use of elamipretide for the treatment of patients with BTHS.

\section{Modulation of cardiolipin by elamipretide}

As noted above, cardiolipin is biosynthesized in a series of steps from phosphatidic acid and remodeled into various species, with muscles containing mostly tetralinolyl cardiolipin (four 18:2 fatty acid chains $(18: 2)_{4} \mathrm{CL}$ ). Cardiolipin peroxidation and depletion have been reported in a variety of pathological conditions, including BTHS, and are associated with energy deficiency $[151,152]$. In dogs with coronary microembolization-induced HF, total cardiolipin and (18:2) ${ }_{4} \mathrm{CL}$ were decreased in LV myocardium [152] (Fig. 2), although the decrease in cardiolipin content is more modest (20 to 30\%) than that which appears in humans. A 3-month treatment with subcutaneous elamipretide normalized total cardiolipin and (18:2) ${ }_{4} \mathrm{CL}$ [152]. In these dogs, the decrease in cardiolipin was driven by changes in the lipid structure on the inner mitochondria membrane because of peroxidation and was not necessarily a reflection of changes in the total LV myocardial pool of mitochondrial protein [152]. This observation is also supported by results showing concordant changes in LV myocardial levels of 4-hydroxynonenal, a major bi-product of lipid peroxidation [152].

The effects of elamipretide on cardiolipin were also investigated in freshly explanted failing and nonfailing ventricular tissue from children and adults [153]. Cardiolipin was quantified using liquid chromatography coupled to electrospray ionization mass spectrometry and cardiolipin species were
Percent of Normal

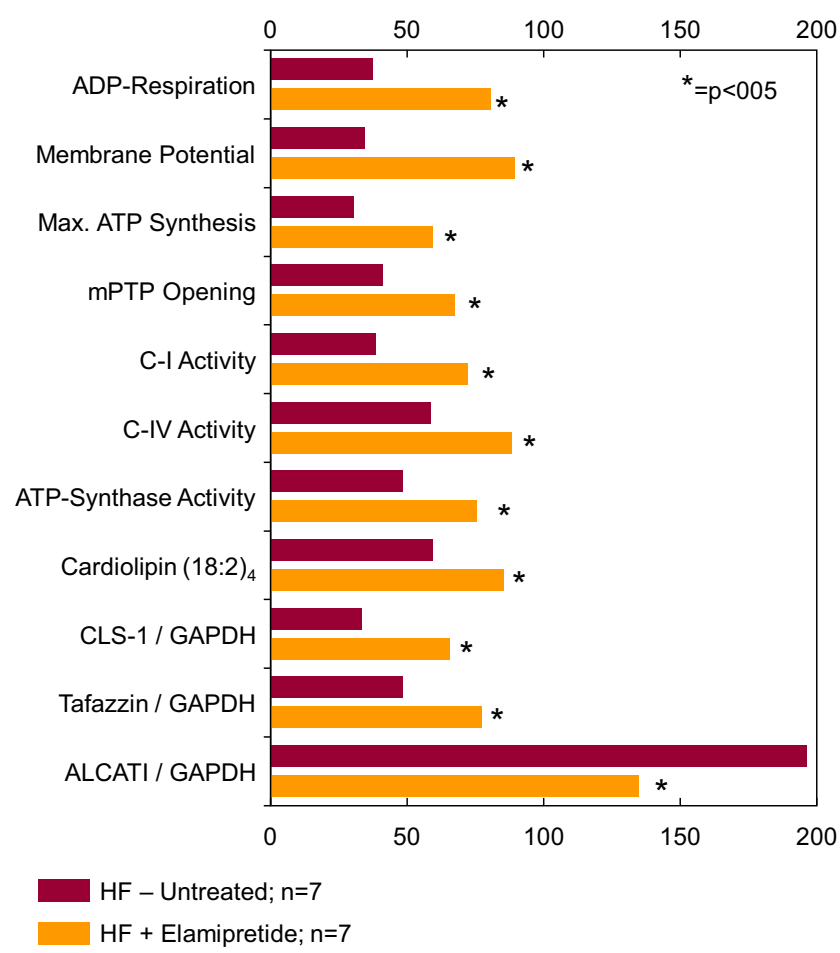

Fig. 2 Bar graph depicting magnitude of change of various measures of mitochondrial function calculated as a percent of levels seen in normal dogs (Percent of Normal). The percentages are shown for untreated dogs with coronary microembolization-induced heart failure (HF-Untreated; $n=7$ ) and for dogs with heart failure treated with elamipretide (HF+ Elamipretide; $n=7)$. Original data in references 163 and 167. The measures are as follows: ADP-dependent state 3 respiration (ADPRespiration); mitochondrial membrane potential; mitochondrial maximum rate of ATP synthesis (Max. ATP Synthesis); mitochondrial permeability transition pore opening (mPTP Opening); mitochondrial complex I (C-I) activity; mitochondrial complex IV (C-IV) activity; ATP synthase activity; cardiolipin (18:2) ; $_{\text {; }}$ cardiolipin synthase-1 levels (CLS-1) normalized to glyceraldehyde 3-phosphate dehydrogenase (GAPDH) levels; tafazzin levels normalized to GAPDH; and acyl CoA lysocardiolipin acyltransferase-1 (ALCAT1) levels normalized to GAPDH

quantified per milligram of protein [153]. The predominant cardiac cardiolipin species, namely $(18: 2)_{4} \mathrm{CL}$, was reported as a percentage of the total (11 major species were used for total) cardiolipin content. The percentage of $(18: 2)_{4} \mathrm{CL}$ was significantly lower in HF tissue, but acute exposure to elamipretide for 4 hours had no effect on tetralinoleoyl cardiolipin in nonfailing or HF samples [153]. It is likely that the absence of change in cardiolipin after exposure to elamipretide in this study with human tissue was due to the short duration of treatment (4 hours) in comparison with longterm treatment (3 months) with elamipretide in animal models.

Several studies have shown that cardiolipin is decreased in diseases associated with mitochondrial dysfunction and that cardiolipin remodeling enzymes are either upregulated or downregulated [154, 155]. Abnormal protein levels and 
messenger RNA (mRNA) expression of cardiolipin synthase1 (CLS-1), an essential enzyme for the synthesis of cardiolipin, and the CL remodeling enzymes tafazzin- 1 and acyl-CoA:lysocardiolipin acyltransferase-1 (ALCAT-1) occur in LV myocardium of the failing heart and in cardiomyopathic hearts of patients with BTHS. In LV myocardium of dogs with experimental HF, protein and mRNA levels of CLS-1 were significantly reduced in untreated HF dogs compared with normal dogs [156] (Fig. 2). Protein and mRNA levels of tafazzin-1 were significantly reduced and ALCAT-1 levels significantly increased in untreated HF dogs compared with normal dogs. These changes are directionally similar to those seen in cardiomyopathic hearts of BTHS. Treatment of dogs with HF with subcutaneous injections of elamipretide for 3 months normalized protein and mRNA levels of CLS-1, tafazzin-1, and ALCAT-1 [156] (Fig. 2). Upregulation of CLS-1 and tafazzin-1 and downregulation of ALCAT-1 by elamipretide favor improvement in cardiolipin synthesis and remodeling that can potentially elicit beneficial effects in cardiomyopathic hearts associated with Barth syndrome.

\section{Effects of elamipretide on mitochondrial dynamics}

Mitochondria are a highly dynamic network that constantly undergo biogenesis, fission, fusion, and mitophagy [154, 157]. Fission and fusion are essential for normal mitochondrial function. A number of proteins and lipids have been shown to be important mediators of these dynamic processes [157], particularly peroxisome proliferator-activated receptor gamma coactivator $1 \alpha$ (PGC- $1 \alpha)$, which is a transcription factor that drives mitochondrial biogenesis. The failing heart, regardless of etiology, manifests dysregulation in both fission- and fusion-regulating proteins. Downregulation of mitochondrial fusion proteins enhances apoptosis, an important contributor to ongoing cardiomyocyte loss and potential mediator of progressive worsening of the HF state [158-160]. Fission-1 (Fis1) and dynamin-related protein-1 (Drp-1) are key proteins that regulate mitochondrial fission while mitofusion-2 (Mfn-2) and dominant optic atrophy-1 (OPA-1) are key proteins that regulate mitochondrial fusion [156]. Another key protein in mitochondrial dynamics is mitofilin, a transmembrane protein of the inner mitochondrial membrane that has a critical role in mitochondrial morphology, fission and fusion, and the formation of tubular cristae and cristae junctions [156]. Downregulation of mitofilin can lead to a disorganized mitochondrial inner membrane and ultrastructural abnormalities that are also manifested in the failing heart as well as in cardiomyopathic hearts of patients with Barth syndrome [156]. Studies in LV myocardium of explanted failed human hearts and hearts from dogs with experimental HF showed marked downregulation of the fusion proteins $\mathrm{Mfn}-2$ and OPA-1, and marked upregulation of the fission proteins Fis1 and Drp-1 [156]. These abnormalities were also accompanied by significant downregulation of PGC- $1 \alpha$ and mitofilin [156]. In dogs with experimental HF, long-term therapy with elamipretide normalized PGC- $1 \alpha$, levels of fission and fusion proteins, and protein levels of mitofilin [156]. Taken together, these findings provide support for elamipretide therapy as a positive modulator of mitochondrial structure and dynamics in the setting of HF of various etiologies.

Cardiolipin, through its influence on mitochondrial fission and fusion, also affects mitophagy, a central step in maintaining mitochondrial quality control process and overall health of the cellular mitochondrial pool by removing mitochondria with damage too severe for correction through biogenic or fusion-mediated repair [161]. Suppression of fission, for instance, accelerates mitophagy by lowering the threshold for mitochondrial removal, a maladaptation likely to promote the elimination of functioning mitochondria, while inhibition of fusion suppresses mitophagy, thus reducing the removal of toxic, ROS-producing mitochondria. Studies in mitochondrial fission- and fusion-defective murine hearts and cells showed that Drp-1-mediated mitochondrial fission is essential to properly target mitophagy and restrain mitochondrial permeability transition pore (MPTP)-mediated cell necrosis [162]. Mfn-2 deletion, on the other hand, resulted in accumulation of defective mitochondria without appropriately increasing mitophagy, while Drp-1 ablation interrupted mitochondrial fission by increased mitophagy, causing a generalized loss of mitochondria [162]. MPTP opening in Drp-1-null mitochondria was associated with mitophagy, cardiomyocyte necrosis, and dilated cardiomyopathy [161]. Normalization of cardiolipin synthesis and remodeling in the failing heart along with normalization of fission and fusion protein levels through treatment with elamipretide argues well for maintenance of essential physiologic levels of mitophagy.

\section{Effects of elamipretide on mitochondrial function}

Functional abnormalities of mitochondria exist in most if not all forms of $\mathrm{HF}$ and cardiomyopathies including Barth syndrome. In the failing heart, mitochondrial functional abnormalities are characterized by poor respiration, opening of the permeability transition pores (mPTP), collapse of mitochondrial membrane potential, reduced rate of ATP synthesis, and excessive production of ROS [152, 156, 163-165]. These abnormalities are typically associated with abnormal synthesis and remodeling of cardiolipin and with increases in cytosolic cytochrome c [152, $166,167]$. The combination of ROS with elevated mitochondrial calcium concentrations leads to $\mathrm{MPTP}$ opening and subsequently reduced membrane potential, which decreases the extra-mitochondrial phosphorylation potential, adversely impacting cell function [168, 169]. A surge in ROS production can lead to cytochrome $\mathrm{c}$ release, which initiates cell death via apoptosis through activation of caspase-3 $[152,170]$. ROS can 
damage the mitochondrial electron transport chain [171-174], trigger lipid peroxidation [175], and cause DNA strand breaks [176], all of which can lead to mitochondrial dysfunction [177]. Elevated mitochondrial ROS production and downstream ROS-mediated damage, mtDNA damage, and defects in electron transport complexes have been reported in animal models of HF [178-180]. Mitochondrial damage to cardiomyocytes from excess ROS production limits ATP production to a level insufficient to support contractile function during times of high oxidative energy requirements [172]. Mitochondria of the failing heart also manifest significant reductions in the activity and abundance of complexes I, II, III, and IV $[152,153]$ as well as the reduction of supercomplex-associated complex IV activity [153]. Cardiolipin is essential for activity of mitochondrial complexes and, in particular, complex I and complex IV. Defects of complex I are integral to the formation of ROS, whereas complex IV is essential for oxidative phosphorylation. In dogs with experimental HF, long-term therapy with elamipretide normalized mitochondrial respiration, mPTP opening, and membrane potential and improved the maximum rate of ATP synthesis [152] (Fig. 2). These improvements were accompanied by a reduction of cytochrome $\mathrm{c}$ release, a reduction of ROS formation, and improvements in mitochondrial complex I and IV activities [152]. Elamipretide also restored, albeit in part, protein levels of key subunits of mitochondrial complexes I through V [152]. Similar observations were made in LV tissue from humans with HF along with improvement of supercomplex-associated complex IV activity [153].

\section{Effects of elamipretide on LV systolic function}

Studies in dogs with coronary microembolization-induced chronic HF with reduced LV ejection fraction (HFrEF) showed that 3 months' monotherapy with daily subcutaneous injections of elamipretide improved LV systolic function and prevented progressive LV dilation without affecting heart rate, blood pressure, or systemic vascular resistance [152]. In these dogs, elamipretide significantly increased LV ejection fraction and LV fractional area of shortening compared with controls, and significantly reduced LV end-systolic volume and plasma concentration of n-terminal brain natriuretic peptide [152]. A phase $1 / 2$ ascending single-dose study of elamipretide (4-h infusions, $0.005,0.05$, and $0.25 \mathrm{mg} / \mathrm{kg} / \mathrm{h}$ ) in 36 patients with HFrEF showed that elamipretide was well tolerated and significantly reduced LV end-diastolic $(-18 \mathrm{~mL} ; P=0.009)$ and endsystolic $(-14 \mathrm{~mL} ; P=0.005)$ volumes in the highest dose cohort and correlated with peak plasma concentrations, supporting a temporal association and dose-effect relationship [181]. No serious adverse events were reported in any of the cohorts and blood pressure and heart rate remained stable. In a more recent randomized phase 2 trial in patients with ischemic or idiopathic dilated cardiomyopathy receiving standard of care treatment for HFrEF, elamipretide was well tolerated but did not improve LV end-systolic volume compared with placebo [181]. None of the patients in this phase 2 trial had BTHS.

\section{Effects of elamipretide on $\mathrm{Ca}^{2+}$-ATPase and inflammatory cytokines}

In tafazzin knockdown mice, a model of Barth syndrome, $\mathrm{Ca}^{2+}$-ATPase or SERCA2a activity was impaired and SERCA2a tyrosine nitration increased compared with wildtype mice [87]. A reduction in SERCA2a expression often leads to poor LV active relaxation and overall LV diastolic dysfunction. Patients with myocardial noncompaction, typically present in Barth syndrome, almost always exhibit diastolic dysfunction [88]. These findings suggest that SERCA may be a viable therapeutic target for the cardiolipin deficiency typically observed in patients with Barth syndrome, particularly those manifesting HF with preserved ejection fraction (HFpEF). In a dog model of HFrEF, SERCA2a protein levels were shown to be significantly decreased in LV myocardium compared with normal dogs, but normalized after long-term treatment with elamipretide [152] (Fig. 3). The effects of elamipretide on diastolic LV function were also examined in a swine model of renovascular hypertension that manifests $\mathrm{HFpEF}$, as evidenced by preserved LV ejection fraction, LV hypertrophy, poor LV relaxation and reduced $\mathrm{Ca}^{2+}$-ATPase activity, and expression and phospholamban phosphorylation at serine 16 [182]. In this swine model, treatment with elamipretide improved LV relaxation, ameliorated cardiac hypertrophy, and normalized phospholamban phosphorylation and $\mathrm{Ca}^{2+}$-ATPase activity and expression without affecting blood pressure or systolic LV function [182]. These results support the use of elamipretide as potential therapy for patients with Barth syndrome that manifest HFpEF.

Increased plasma levels of pro-inflammatory cytokines are a well-known feature of acquired HF and contribute to mitochondrial dysfunction and ultimately to the progressive worsening of the HF state. Given that BTHS is characterized by cardiomyopathies, it would not be surprising to observe increased levels of TNF- $\alpha$ and IL- 6 in this disease state. Higher levels of TNF- $\alpha$ and IL- 6 have been reported in BTHS and implicated in the pathophysiology of the disease. In dogs with microembolization-induced heart failure, plasma levels of the cytokines TNF- $\alpha$, IL-6, and c-reactive protein (CRP) were significantly elevated compared with normal baseline levels [152]. In these HF dogs, levels of all 3 cytokines were normalized following long-term treatment with elamipretide [152] (Fig. 3). Elevated levels of plasma mitochondrial DNA DAMPs specifically within the COX1 and ND1 genes were markedly elevated in dogs with HF compared with normal baseline levels. In these HF dogs, long-term treatment with elamipretide normalized plasma levels of both COX1 and ND1 DAMPs (unpublished observation by the author) (Fig. 3). 
Fig. 3 Top: Bar graph depicting magnitude of change of plasma cytokines, plasma natriuretic peptide, plasma reactive oxygen species (ROS), and left ventricular tissue levels of calcium ATPase (SERCA-2a) calculated as a percent of levels seen in normal dogs (Percent of Normal). The percentages are shown for untreated dogs with coronary microembolizationinduced heart failure (HFUntreated, $n=7$ ) and for dogs with heart failure treated with elamipretide (HF+Elamipretide, $n=7$ ). Original data in reference 151. nt-pro BNP, n-terminal probrain natriuretic peptide; TNF- $\alpha$, tumor necrosis factor alpha; interlukin-6; CRP, c-reactive protein. Bottom: Bar graph depicting magnitude of change of two plasma mitochondrial fragments also referred to as damage-associated molecular patters (DAMPs) calculated as a percent of levels seen in normal dogs (Percent of Normal). CVOX1, subunit of cytochrome c oxidase (complex IV); ND1, subunit of complex I
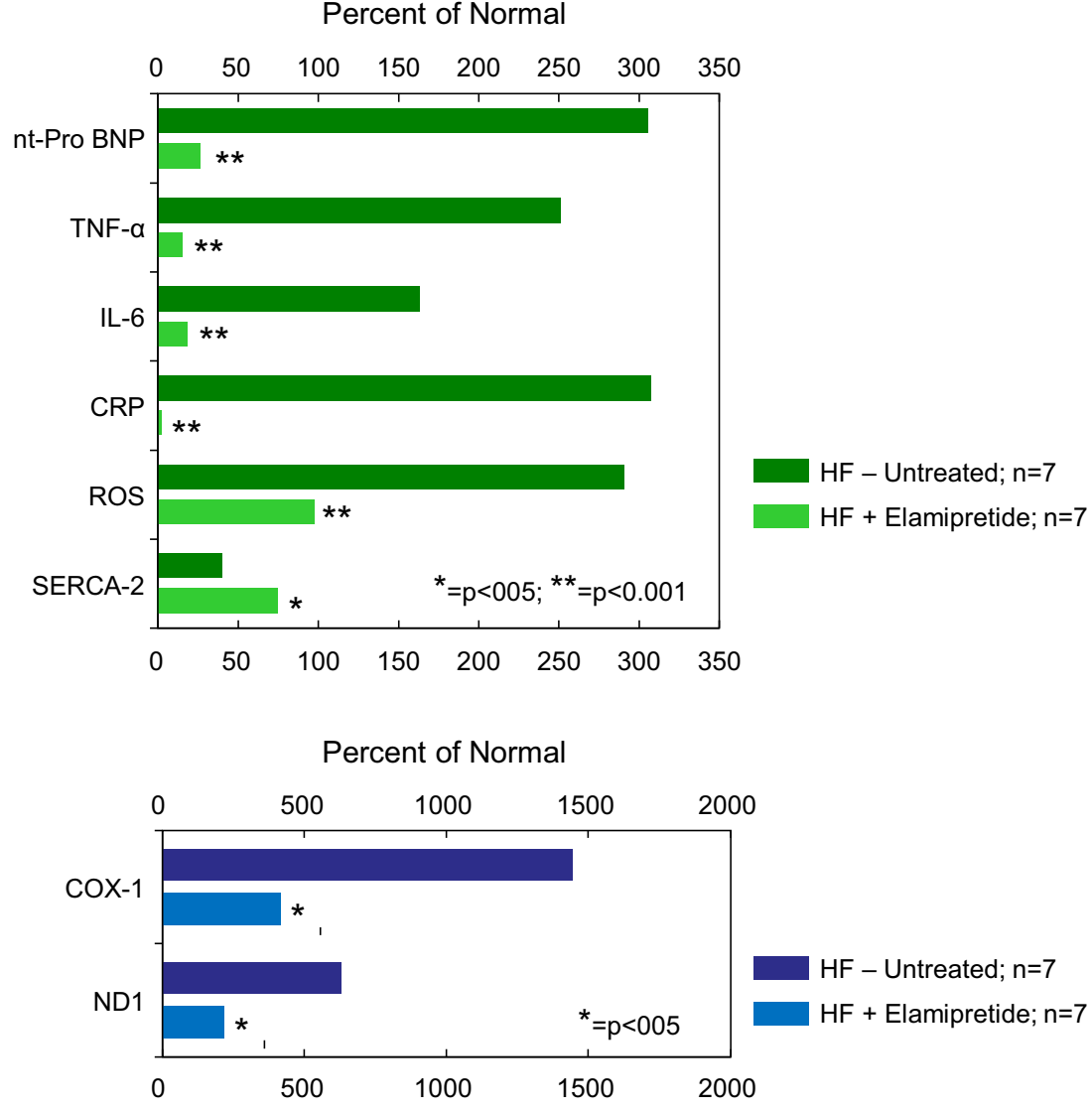

\section{Elamipretide and skeletal muscle}

As alluded to earlier, exercise intolerance is a hallmark of most, if not all, cardiomyopathies including those which occur in Barth syndrome. Patients with Barth syndrome have multiple signs of skeletal muscle impairments, including impaired functional exercise capacity and reduced daily activity, with a greater reliance on skeletal muscle glycolytic metabolism than those without Barth syndrome. This higher glycolytic capacity might be compensatory for an impaired capacity to generate ATP via oxidative phosphorylation. Mitochondrial respiration has been shown to be impaired in the skeletal muscle of Barth syndrome patients due to multiple factors that include mitochondrial supercomplex destabilization, higher degradation and reduced levels of mitochondrial cardiolipin, abnormal mitochondrial morphology, excessive production of reactive oxygen species, and defects in ATP synthase activity [50, 66, 131-133]. In dogs with HF, long-term treatment with elamipretide restored skeletal muscle fiber-type composition to a more normal distribution (increased proportion of skeletal muscle type 1 fibers relative to skeletal muscle type 2 fibers) [183]. Elamipretide also normalized skeletal muscle mitochondrial function as evidenced by significant greater improvements in mitochondrial respiration, membrane potential, and maximal rate of ATP synthesis when compared with untreated HF dogs [183]. In dogs with HF, therapy with elamipretide also increased skeletal muscle activity of cytochrome c oxidase (complex IV of the ETC) [182]. In a phase I/ II multicenter, randomized, double-blind, placebo-controlled trial of elamipretide in 36 patients with genetically confirmed primary mitochondrial myopathy (not including Barth syndrome), participants who received elamipretide showed a significant dose-dependent increase in distance walked on the 6min walk test (6MWT) compared with placebo [184]. These findings, when viewed in concert, suggest that therapy with elamipretide can improve skeletal muscle morphology and metabolism and, in doing so, potentially set the stage for an improvement of exercise tolerance in patients with Barth syndrome.

\section{Treating Barth syndrome with elamipretide}

A phase 2/3 randomized, double-blind, placebo-controlled crossover trial followed by an open-label treatment extension of elamipretide in subjects with genetically confirmed BTHS (TAZPOWER Trial) is ongoing. The TAZPOWER Trial was designed to evaluate the efficacy and safety of the clinicalphase, investigational product elamipretide in patients with Barth syndrome; 12 patients (mean age 19.5 years, range 12 
to 35 years) with genetically confirmed BTHS were enrolled. The phenotype in these patients was that of hypertrophic cardiomyopathy characterized by lower than normal LV end-diastolic volume and normal LV ejection fraction. In Part 1 of the trial, participants received once-daily subcutaneous injections of $40 \mathrm{mg}$ elamipretide for 12 weeks, followed by a 12 -week treatment with placebo, or vice versa, with a 4week "washout" that occurred between each treatment. The second part of the ongoing trial involves an open-label extension for up to 168 weeks, in which 10 of the 12 patients participated. The primary objective, assessed at week 12 , is the change from baseline in the 6MWT. Additional outcome measures include functional measures of muscle strength and heart performance, and subjective measures of patientreported outcomes, as well as adverse effects.

Cardiac dysfunction has been shown to be a primary cause of early mortality in this patient population and improvements in left ventricular end-diastolic volume (LVEDV) and stroke volume are major determinants of peak exercise capacity in patients with hypertrophic cardiomyopathy. Recently reported trial results showed that elamipretide improves overall cardiac function, with averaged indexed cardiac stroke volumes increasing by $27 \%$ - from $40.8 \mathrm{~mL}$ at the start of the trial (baseline) to $51.8 \mathrm{~mL}$-after 36 weeks of treatment with elamipretide in the open-label extension. In this study, elamipretide was generally well tolerated with the majority of adverse events being mild to moderate in severity. The most commonly reported adverse event was injection site reactions, occurring in $100 \%$ of patients while taking elamipretide [185, 186]. The U.S. Food and Drug Administration (FDA) has granted Fast Track and Orphan Drug designations for elamipretide for the treatment of patients with Barth syndrome. The encouraging clinical results seen in patients with BTHS treated with elamipretide support the potential use of this drug for the clinical management of this rare disease syndrome.

Funding This work is supported in part by Stealth BioTherapeutics, Inc. and by National Heart Lung and Blood Institute 1RO1HL132154-04

Open Access This article is licensed under a Creative Commons Attribution 4.0 International License, which permits use, sharing, adaptation, distribution and reproduction in any medium or format, as long as you give appropriate credit to the original author(s) and the source, provide a link to the Creative Commons licence, and indicate if changes were made. The images or other third party material in this article are included in the article's Creative Commons licence, unless indicated otherwise in a credit line to the material. If material is not included in the article's Creative Commons licence and your intended use is not permitted by statutory regulation or exceeds the permitted use, you will need to obtain permission directly from the copyright holder. To view a copy of this licence, visit http://creativecommons.org/licenses/by/4.0/.

\section{References}

1. Dubek J, Maack C (2017) Barth syndrome cardiomyopathy. Cardiovasc Res 113:399-410

2. Clarke SL, Bowron A, Gonzalez IL, Groves SJ, Newbury-Ecob R, Clayton N, Martin RP, Tsai-Goodman B, Garratt V, Ashworth M, Bowen VM, McCurdy KR, Damin MK, Spencer CT, Toth MJ, Kelley RI, Steward CG (2013) Barth syndrome. Orphanet J Rare Dis 8:23

3. Barth P, Van den Bogert C, Bolhuis P, Scholte H, van Gennip A, Schutgens R, Ketel A (1996) X-linked cardioskeletal myopathy and neutropenia (Barth syndrome): respiratory-chain abnormalities in cultured fibroblasts. J Inherit Metab Dis 19:157-160

4. Bione S, D'Adamo P, Maestrini E, Gedeon AK, Bolhuis PA, Toniolo D (1996) A novel X-linked gene, G4.5. is responsible for Barth syndrome. Nat Genet 12:385-389

5. Whited K, Baile MG, Currier P, Claypool SM (2013) Seven functional classes of Barth syndrome mutation. Hum Mol Genet 22: 483-492

6. Xu Y, Kelley RI, Blanck TJ, Schlame M (2003) Remodeling of cardiolipin by phospholipid transacylation. J Biol Chem 278: 51380-51385

7. Xu Y, Malhotra A, Ren M, Schlame M (2006) The enzymatic function of tafazzin. J Biol Chem 281:39217-39224

8. Zhou B, Tian R (2018) Mitochondrial dysfunction in pathophysiology of heart failure. J Clin Invest 128:3716-3726

9. Brown DA, Perry JB, Allen ME, Sabbah HN, Stauffer BL, Shaikh SR, Cleland JG, Colucci WS, Butler J, Voors AA, Anker SD, Pitt B, Pieske B, Filippatos G, Greene SJ, Gheorghiade M (2017) Expert consensus document: mitochondrial function as a therapeutic target in heart failure. Nat Rev Cardiol 14:238-250

10. Barth E, Stammler G, Speiser B, Schaper J (1992) Ultrastructural quantitation of mitochondria and myofilaments in cardiac muscle from 10 different animal species including man. J Mol Cell Cardiol 24:669-681

11. Schaper J, Meiser E, Stammler G (1985) Ultrastructural morphometric analysis of myocardium from dogs, rats, hamsters, mice, and from human hearts. Circ Res 56:377-391

12. Johannsen DL, Ravussin E (2009) The role of mitochondria in health and disease. Curr Opin Pharmacol 9:780-786

13. Okonko DO, Shah AM (2015) Heart failure: mitochondrial dysfunction and oxidative stress in CHF. Nat Rev Cardiol 12:6-8

14. Sabbah HN (2016) Targeting mitochondrial dysfunction in the treatment of heart failure. Expert Rev Cardiovasc Ther 14:13051313

15. Birk AV, Chao WM, Bracken C, Warren JD, Szeto HH (2014) Targeting mitochondrial cardiolipin and the cytochrome $\mathrm{c} /$ cardiolipin complex to promote electron transport and optimize mitochondrial ATP synthesis. Br J Pharmacol 171:2017-2028

16. Neubauer $S$ (2007) The failing heart-an engine out of fuel. N Engl J Med 356:1140-1151

17. Opie LH (1997) Fuels: Aerobic and anaerobic metabolism. The heart: physiology, from cell to circulation, 3rd edn. LippincottRaven, Philadelphia, pp 295-342

18. Marin-Garcia J, Goldenthal MJ (2008) Mitochondrial centrality in heart failure. Heart Fail Rev 13:137-150

19. Sabbah HN, Gupta RC, Singh-Gupta V, Zhang K (2019) Effects of elamipretide on skeletal muscle in dogs with experimentally induced heart failure. ESC Heart Fail 6:328-335

20. Bashir A, Bohnert KL, Reeds DN, Peterson LR, Bittel AJ, de las Fuentes L, Pacak CA, Byrne BJ, Cade WT (2017) Impaired cardiac and skeletal muscle bioenergetics in children, adolescents, and young adults with Barth syndrome. Phys Rep 5:e13130 
21. Kolwicz SC Jr, Purohit S, Tian R (2013) Cardiac metabolism and its interactions with contraction, growth, and survival of cardiomyocytes. Circ Res 113(9):603-616

22. Liu SZ, Marcinek DJ (2017) Skeletal muscle bioenergetics in aging and heart failure. Heart Fail Rev 22:167-178

23. Spencer CT, Byrne BJ, Bryant RM, Margossian R, Maisenbacher M, Breitenger P, Benni PB, Redfearn S, Marcus E, Cade WT (2011) Impaired cardiac reserve and severely diminished skeletal muscle $\mathrm{O}(2)$ utilization mediate exercise intolerance in Barth syndrome. Am J Physiol Heart Circ Physiol 301:H2122-H2129

24. Suzuki-Hatano S, Saha M, Rizzo SA, Witko RL, Gosiker BJ, Ramanathan M, Soustek MS, Jones MD, Kang PB, Byrne BJ, Cade WT, Pacak CA (2019) AAV-mediated TAZ gene replacement restores mitochondrial and cardioskeletal function in Barth syndrome. Hum Gene Ther 30:139-154

25. Hijikata A, Yura K, Ohara O, Go M (2015) Structural and functional analyses of Barth syndrome-causing mutations and alternative splicing in the tafazzin acyltransferase domain. Meta Gene 4: 92-106

26. Dinca AA, Chien WM, Chin MT (2018) Identification of novel mitochondrial localization signals in human tafazzin, the cause of the inherited cardiomyopathic disorder Barth syndrome. J Mol Cell Cardiol 114:83-92

27. Gawrisch K (2012) Tafazzin senses curvature. Nat Chem Biol 20128(10):811-812

28. Abe M, Hasegawa Y, Oku M, Sawada Y, Tanaka E, Sakai Y, Miyoshi H (2016) Mechanism for remodeling of the acyl chain composition of cardiolipin catalyzed by saccharomyces cerevisiae tafazzin. J Biol Chem 291(30):15491-15502

29. Herndon JD, Claypool SM, Koehler CM (2013) The Tazlp transacylase is imported and sorted into the outer mitochondrial membrane via a membrane anchor domain. Eukaryot Cell 12: $1600-1608$

30. Huang W, Lv X, Liu C, Zha Z, Zhang H, Jiang Y, Xiong Y, Lei QY, Guan KL (2012) The N-terminal phosphodegron targets TAZ/WWTR1 protein for SCF $\beta$-TrCP-dependent degradation in response to phosphatidylinositol 3-kinase inhibition. J Biol Chem 287:26245-26253

31. Ge L, Li DS, Chen F, Feng JD, Li B, Wang TJ (2017) TAZ overexpression is associated with epithelial-mesenchymal transition in cisplatin-resistant gastric cancer cells. Int J Oncol 51:307315

32. Chen M, Zhang Y, Zheng PS (2017) Tafazzin (TAZ) promotes the tumorigenicity of cervical cancer cells and inhibits apoptosis. PLoS One 12:e177171

33. Ye C, Shen Z, Greenberg ML (2016) Cardiolipin remodeling: a regulatory hub for modulating cardiolipin metabolism and function. J Bioenerg Biomembr 48:113-123

34. Ronvelia D, Greenwood J, Platt J, Hakim S, Zaragoza MV (2012) Intrafamilial variability for novel TAZ gene mutation: Barth syndrome with dilated cardiomyopathy and heart failure in an infant and left ventricular noncompaction in his great-uncle. Mol Genet Metab 107:428-432

35. Ikon N, Ryan RO (2017) Barth syndrome: connecting cardiolipin to cardiomyopathy. Lipids 52:99-108

36. Houtkooper RH, Vaz FM (2008) Cardiolipin, the heart of mitochondrial metabolism. Cell Mol Life Sci 65:2493-2506

37. Schlame M (2009) Formation of molecular species of mitochondrial cardiolipin 2. A mathematical model of pattern formation by phospholipid transacylation. Biochem Biophys Acta 1791:321325

38. Gaspard GJ, McMaster CR (2015) Cardiolipin metabolism and its causal role in the etiology of the inherited cardiomyopathy Barth syndrome. Chem Phys Lipids 193:1-10

39. Cao J, Liu Y, Lockwood J, Burn P, Shi Y (2004) A novel cardiolipin-remodeling pathway revealed by a gene encoding an endoplasmic reticulum-associated acyl-CoA:lysocardiolipin acyltransferase (ALCAT1) in mouse. J Biol Chem 279:31727-31734

40. Taylor WA, Hatch GM (2009) Identification of the human mitochondrial linoleoyl-coenzyme a monolysocardiolipin acyltransferase (MLCLAT-1). J Biol Chem 284:30360-30371

41. Mejia EM, Cole LK, Hatch GM (2014) Cardiolipin metabolism and the role it plays in heart failure and mitochondrial supercomplex formation. Cardiovasc Hematol Disord Drug Targets 14:98-106

42. Kiebish MA, Han X, Cheng H, Chuang JH, Seyfried TN (2008) Brain mitochondrial lipid abnormalities in mice susceptible to spontaneous gliomas. Lipids. 43:951-959

43. Schlame M, Ren M (2006) Barth syndrome, a human disorder of cardiolipin metabolism. FEBS Lett 580:5450-5455

44. Hauff KD, Hatch GM (2006) Cardiolipin metabolism and Barth syndrome. Prog Lipid Res 45:91-101

45. Schlame M (2008) Cardiolipin synthesis for the assembly of bacterial and mitochondrial membranes. J Lipid Res 49:1607-1620

46. Schlame M, Ren M, Xu Y, Greenberg ML, Haller I (2005) Molecular symmetry in mitochondrial cardiolipins. Chem Phys Lipids 138:38-49

47. Schlame M, Kelley RI, Feigenbaum A, Towbin JA, Heerdt PM, Schieble T, Wanders RJ, DiMauro S, Blanck TJ (2003) Phospholipid abnormalities in children with Barth syndrome. J Am Coll Cardiol 42:1994-1999

48. Chacinska A, Koehler CM, Milenkovic D, Lithgow T, Pfanner N (2009) Importing mitochondrial proteins: machineries and mechanisms. Cell 138:628-644

49. Neupert W, Herrmann JM (2007) Translocation of proteins into mitochondria. Annu Rev Biochem 76:723-749

50. Bissler JJ, Tsoras M, Göring HHH, Hug P, Chuck G, Tombragel E, McGraw C, Schlotman J, Ralston MA, Hug G (2002) Infantile dilated X-linked cardiomyopathy, G4.5 mutations, altered lipids, and ultrastructural malformations of mitochondria in heart, liver, and skeletal muscle. Lab Investig 82:335-344

51. Haines TH, Dencher NA (2002) Cardiolipin: a proton trap for oxidative phosphorylation. FEBS Lett:52835-52839

52. Fry M, Green DE (1980) Cardiolipin requirement by cytochrome oxidase and the catalytic role of phospholipid. Biochem Biophys Res Commun 93:1238-1246

53. Fry M, Blondin GA, Green DE (1980) The localization of tightly bound cardiolipin in cytochrome oxidase. J Biol Chem 255:99679970

54. Fry M, Green DE (1981) Cardiolipin requirement for electron transfer in complex I and III of the mitochondrial respiratory chain. J Biol Chem 256:1874-1880

55. Chicco AJ, Sparagna GC (2007) Role of cardiolipin alterations in mitochondrial dysfunction and disease. Am J Phys Cell Physiol 292:C33-C44

56. Hoch FL (1992) Cardiolipins and biomembrane function. Biochim Biophys Acta 1113:71-133

57. McKenzie M, Lazarou M, Thorburn DR, Ryan MT (2006) Mitochondrial respiratory chain supercomplexes are destabilized in Barth syndrome patients. J Mol Biol 361:462-469

58. Shinzawa-Itoh K, Aoyama H, Muramoto K, Terada H, Kurauchi T, Tadehara Y, Yamasaki A, Sugimura T, Kurono S, Tsujimoto K, Mizushima T, Yamashita E, Tsukihara T, Yoshikawa S (2007) Structures and physiological roles of 13 integral lipids of bovine heart cytochrome c oxidase. EMBO J 26:1713-1725

59. Zhang M, Mileykovskaya E, Dowhan W (2002) Gluing the respiratory chain together. Cardiolipin is required for supercomplex formation in the inner mitochondrial membrane. J Biol Chem 277:43553-43556

60. Pfeiffer K, Gohil V, Stuart RA, Hunte C, Brandt U, Greenberg ML, Schagger H (2003) Cardiolipin stabilizes respiratory chain supercomplexes. J Biol Chem 278:52873-52880 
61. Hoch FL (1998) Cardiolipins and mitochondrial proton-selective leakage. J Bioenerg Biomembr 30:511-532

62. Neuwald AF (1997) Barth syndrome may be due to an acyltransferase deficiency. Curr Biol 7:R465-R466

63. Houtkooper RH, Turkenburg M, Poll-The BT, Karall D, PérezCerdá C, Morrone A, Malvagia S, Wanders RJ, Kulik W, Vaz FM (2009) The enigmatic role of tafazzin in cardiolipin metabolism. Biochim Biophys Acta 1788:2003-2014

64. Saini-Chohan HK, Holmes MG, Chicco AJ, Taylor WA, Moore RL, McCune SA, Hickson-Bick DL, Hatch GM, Sparagna GC (2009) Cardiolipin biosynthesis and remodeling enzymes are altered during development of heart failure. J Lipid Res 50:16001608

65. Valianpour F, Mitsakos V, Schlemmer D, Towbin JA, Taylor JM, Ekert PG, Thorburn DR, Munnich A, Wanders RJ, Barth PG, Vaz FM (2005) Monolysocardiolipins accumulate in Barth syndrome but do not lead to enhanced apoptosis. J Lipid Res 46:1182-1195

66. Wang G, McCain ML, Yang L, He A, Pasqualini FS, Agarwal A et al (2014) Modeling the mitochondrial cardiomyopathy of Barth syndrome with induced pluripotent stem cell and heart-on-chip technologies. Nat Med 20:616-623

67. Jefferies JL, Towbin JA (2010) Dilated cardiomyopathy. Lancet. 375:752-762

68. Spencer CT, Bryant RM, Day J et al (2006) Cardiac and clinical phenotype in Barth syndrome. Pediatrics. 118(2):e337-e346

69. Ades LC, Gedeon AK, Wilson MJ, Latham M, Partington MW, Mulley JC, Nelson J, Lui K, Sillence DO (1993) Barth syndrome: clinical features and confirmation of gene localisation to distal Xq28. Am J Med Genet 45:327-334

70. Bleyl SB, Mumford BR, Thompson V, Carey JC, Pysher TJ, Chin TK, Ward K (1997) Neonatal, lethal noncompaction of the left ventricular myocardium is allelic with Barth syndrome. Am J Hum Genet 61:868-872

71. Jefferies JL (2013) Barth syndrome. Am J Med Genet C: Semin Med Genet 163:198-205

72. Towbin JA, Bowles NE (2002) The failing heart. Nature. 415: 227-233

73. Pignatelli RH, McMahon CJ, Dreyer WJ, Denfield SW, Price J, Belmont JW, Craigen WJ, Wu J, El Said H, Bezold LI, Clunie S, Fernbach S, Bowles NE, Towbin JA (2003) Clinical characterization of left ventricular noncompaction in children: a relatively common form of cardiomyopathy. Circulation. 108:2672-2678

74. Klaassen S, Probst S, Oechslin E, Gerull B, Krings G, Schuler P, Greutmann M, Hurlimann D, Yegitbasi M, Pons L, Gramlich M, Drenckhahn JD, Heuser A, Berger F, Jenni R, Thierfelder L (2008) Mutations in sarcomere protein genes in left ventricular noncompaction. Circulation. 117:2893-2901

75. Gersh BJ, Maron BJ, Bonow RO, Dearani JA, Fifer MA, Link MS, Naidu SS, Nishimura RA, Ommen SR, Rakowski H, Seidman CE, Towbin JA, Udelson JE, Yancy CW, American College of Cardiology Foundation/American Heart Association Task Force on Practice Guidelines; American Association for Thoracic Surgery; American Society of Echocardiography; American Society of Nuclear Cardiology; Heart Failure Society of America; Heart Rhythm Society; Society for Cardiovascular Angiography and Interventions; Society of Thoracic Surgeons (2011) 2011 ACCF/AHA guideline for the diagnosis and treatment of hypertrophic cardiomyopathy: executive summary: a report of the American College of Cardiology Foundation/American Heart Association Task Force on Practice Guidelines. Circulation. 124:2761-2796

76. Brescia ST, Rossano JW, Pignatelli R, Jefferies JL, Price JF, Decker JA, Denfield SW, Dreyer WJ, Smith O, Towbin JA, Kim JJ (2013) Mortality and sudden death in pediatric left ventricular noncompaction in a tertiary referral center. Circulation. 127:2202-2208
77. Frank K, Kranias EG (2000) Phospholamban and cardiac contractility. Ann Med 32:572-578

78. MacLennan DH, Kranias EG (2003) Phospholamban: a crucial regulator of cardiac contractility. Nat Rev Mol Cell Biol 4:566577

79. Tupling AR, Vigna C, Ford RJ, Tsuchiya SC, Graham DA, Denniss SG, Rush JW (2007) Effects of buthionine sulfoximine treatment on diaphragm contractility and SR Ca2+ pump function in rats. J Appl Physiol (1985) 103:1921-1928

80. Viner RI, Ferrington DA, Huhmer AF, Bigelow DJ, Schoneich C (1996) Accumulation of nitrotyrosine on the SERCA2a isoform of SR Ca-ATPase of rat skeletal muscle during aging: a peroxynitrite-mediated process? FEBS Lett 379:286-290

81. Viner RI, Williams TD, Schöneich C (1999) Peroxynitrite modification of protein thiols: oxidation, nitrosylation, and SGlutathiolation of functionally important cysteine residue(s) in the sarcoplasmic reticulum $\mathrm{Ca}^{2+}$-ATPase. FEBS Lett 379:286290

82. Pacher P, Beckman JS, Liaudet L (2007) Nitric oxide and peroxynitrite in health and disease. Physiol Rev 87:315-424

83. Phoon CK, Acehan D, Schlame M, Stokes DL, EdelmanNovemsky I, Yu D, Xu Y, Viswanathan N, Ren M (2012) Tafazzin knockdown in mice leads to a developmental cardiomyopathy with early diastolic dysfunction preceding myocardial noncompaction. J Am Heart Assoc 1(2):jah3-e000455

84. Powers C, Huang Y, Strauss AW, Khuchua Z (2013) Diminished exercise capacity and mitochondrial bc1 complex deficiency in tafazzin-knockdown mice. Front Physiol 4:74

85. Kelley RI, Cheatham JP, Clark BJ, Nigro MA, Powell BR, Sherwood GW, Sladky JT, Swisher WP (1991) X-linked dilated cardiomyopathy with neutropenia, growth retardation, and 3methylglutaconic aciduria. J Pediatr 119:738-747

86. Lokuta AJ, Maertz NA, Meethal SV, Potter KT, Kamp TJ, Valdivia HH, Haworth RA (2005) Increased nitration of sarcoplasmic reticulum $\mathrm{Ca} 2+-\mathrm{ATPase}$ in human heart failure. Circulation 111:988-995

87. Acehan D, Vaz F, Houtkooper RH, James J, Moore V, Tokunaga C, Kulik W, Wansapura J, Toth MJ, Strauss A, Khuchua Z (2011) Cardiac and skeletal muscle defects in a mouse model of human Barth syndrome. J Biol Chem 286:899-908

88. Braun JL, Hamstra SI, Messner HN, Fajardo VA (2019) SERCA2a tyrosine nitration coincides with impairments in maximal SERCA activity in left ventricles from tafazzin-deficient mice. Phys Rep 7:e14215

89. Ichida F, Hamamichi Y, Miyawaki T, Ono Y, Kamiya T, Akagi T, Hamada H, Hirose O, Isobe T, Yamada K, Kurotobi S, Mito H, Miyake T, Murakami Y, Nishi T, Shinohara M, Seguchi M, Tashiro S, Tomimatsu H (1999) Clinical features of isolated noncompaction of the ventricular myocardium: long-term clinical course, hemodynamic properties, and genetic background. J Am Coll Cardiol 34:233-240

90. Ishiwata T, Nakazawa M, Pu WT, Tevosian SG, Izumo S (2003) Developmental changes in ventricular diastolic function correlate with changes in ventricular myoarchitecture in normal mouse embryos. Circ Res 93:857-865

91. Zhang JM, An J (2007) Cytokines, inflammation, and pain. Internl Anesth Clin 45:27-37

92. Aukrust P, Ueland T, Lien E, Bendtzen K, Muller F, Andreassen AK, Nordøy I, Aass H, Espevik T, Simonsen S, Frøland SS, Gullestad L (1999) Cytokine network in congestive heart failure secondary to ischemic or idiopathic dilated cardiomyopathy. Am J Cardiol 83:376-382

93. Testa M, Yeh M, Lee P, Fanelli R, Loperfido F, Berman JW, LeJemtel T (1996) Circulating levels of cytokines and their endogenous modulators in patients with mild to severe congestive 
heart failure due to coronary artery disease or hypertension. J Am Coll Cardiol 28:964-971

94. Torre-Amione G, Kapadia S, Benedict C, Oral H, Young JB, Mann DL (1996) Proinflammatory cytokine levels in patients with depressed left ventricular ejection fraction: a report from the Studies of Left Ventricular Dysfunction (SOLVD). J Am Coll Cardiol 27:1201-1206

95. Bozkurt B, Kribbs SB, Clubb FJ, Michael LH, Didenko VV, Hornsby PJ, Seta Y, Oral H, Spinale FG, Mann DL (1998) Pathophysiologically relevant concentrations of tumor necrosis factor-alpha promote progressive dysfunction and remodelling in rats. Circulation 97:1382-1391

96. Kubota T, McTernan CF, Frye CS, Slawson SE, Lemster BH, Koretsky AP, Demetris AJ, Feldman AM (1997) Dilated cardiomyopathy in transgenic mice with cardiac-specific overexpression of tumor necrosis factor-alpha. Circ Res 81:627-635

97. Fischer P, Hilfiker-Kleiner D (2008) Role of gp130- mediated signalling pathways in the heart and its impact on potential therapeutic aspects. Br J Pharmacol 153(suppl 1):S414-S427

98. Mann DL (2002) Inflammatory mediators and the failing heart: past, present, and the foreseeable future. Circ Res 91:988-998

99. Dinh W, Futh R, Nickl W, Krahn T, Ellinghaus P, Scheffold T, Bansemir L, Bufe A, Barroso MC, Lankisch M (2011) Elevated plasma levels of TNF-alpha and interleukin-6 in patients with diastolic dysfunction and glucose metabolism disorders. Diabet Med 28:311-318

100. Zibadi S, Vazquez R, Larson DF, Watson RR (2010) Tlymphocyte regulation of lysyl oxidase in diet-induced cardiac fibrosis. Cardiovasc Toxicol 10:190-198

101. Wilson LD, Al-Majid S, Rakovski CS, Schwindt CD (2012) Higher IL-6 and IL6:IGF ratio in patients with Barth syndrome. J Inflamm 9(1):25

102. Lang CH, Frost RA (2007) Sepsis-induced suppression of skeletal muscle translation initiation mediated by tumor necrosis factor alpha. Metabolism. 56:49-57

103. Garcia-Martinez C, Lopez-Soriano FJ, Argiles JM (1993) Acute treatment with tumour necrosis factor-alpha induces changes in protein metabolism in rat skeletal muscle. Mol Cell Biochem 125:11-18

104. Janssen SP, Gayan-Ramirez G, Van den Bergh A, Herijgers P, Maes K, Verbeken E, Decramer M (2005) Interleukin-6 causes myocardial failure and skeletal muscle atrophy in rats. Circulation. 111:996-1005

105. Lang CH, Frost RA, Vary TC (2007) Regulation of muscle protein synthesis during sepsis and inflammation. Am J Physiol Endocrinol Metab 293:E453-E459

106. Jurasinski CV, Vary TC (1995) Insulin-like growth factor I accelerates protein synthesis in skeletal muscle during sepsis. Am J Phys 269:E977-E981

107. Grounds MD, Radley HG, Gebski BL, Bogoyevitch MA, Shavlakadze T (2008) Implications of cross-talk between tumour necrosis factor and insulin-like growth factor-1 signalling in skeletal muscle. Clin Exp Pharmacol Physiol 35:846-851

108. Grazioli S, Pugin J (2018) Mitochondrial damage-associated molecular patterns: from inflammatory signaling to human diseases. Front Immunol 9:832

109. Nakayama H, Otsu K (2018) Mitochondrial DNA as an inflammatory mediator in cardiovascular diseases. Biochem J 475:839852

110. Collins LV, Hajizadeh S, Holme E, Jonsson IM, Tarkowski A (2004) Endogenously oxidized mitochondrial DNA induces in vivo and in vitro inflammatory responses. J Leukoc Biol 75: 995-1000

111. Zhang Q, Raoof M, Chen Y, Sumi Y, Sursal T, Junger W et al (2010) Circulating mitochondrial DAMPs cause inflammatory responses to injury. Nature 464:104-107
112. Peitsch MC, Tschopp J, Kress A, Isliker H (1988) Antibodyindependent activation of the complement system by mitochondria is mediated by cardiolipin. Biochem J 249:495-500

113. Chen GY, Nuñez G (2010) Sterile inflammation: sensing and reacting to damage. Nat Rev Immunol 10:826-837

114. West AP, Shadel GS (2017) Mitochondrial DNA in innate immune responses and inflammatory pathology. Nat Rev Immunol 17:363-375

115. Mathew A, Lindsley TA, Sheridan A, Bhoiwala DL, Hushmendy SF, Yager EJ et al (2012) Degraded mitochondrial DNA is a newly identified subtype of the damage associated molecular pattern (DAMP) family and possible trigger of neurodegeneration. J Alzheimers Dis 30:617-627

116. Barth Syndrome Foundation. The Voice of the Patient: Barth Syndrome. Externally-Led Public Meeting: July 18, 2018. Report Date: March 8, 2019

117. Sabbah HN (2020) Targeting the mitochondria in heart failure: a translational perspective. JACC 5:88-106

118. Sabbah HN, Hansen-Smith F, Sharov VG, Kono T, Lesch M, Gengo PJ, Steffen RP, Levine TB, Goldstein S (1993) Decreased proportion of type I myofibers in skeletal muscle of dogs with chronic heart failure. Circulation 87:1729-1737

119. Sullivan MJ, Green HJ, Cobb FR (1990) Skeletal muscle biochemistry and histology in ambulatory patients with long-term heart failure. Circulation 81:518-527

120. Hambrecht R, Fiehn E, Yu J, Niebauer J, Weigl C, Hilbrich L, Adams V, Riede U, Schuler G (1997) Effects of endurance training on mitochondrial ultrastructure and fiber type distribution in skeletal muscle of patients with stable chronic heart failure. J Am Coll Cardiol 29:1067-1073

121. Sullivan MJ, Duscha BD, Klitgaard H, Kraus WE, Cobb FR, Saltin B (1997) Altered expression of myosin heavy chain in human skeletal muscle in chronic heart failure. Med Sci Sports Exerc 29:860-866

122. Marcinek DJ, Schenkman KA, Ciesielski WA, Lee D, Conley KE (2005) Reduced mitochondrial coupling in vivo alters cellular energetics in aged mouse skeletal muscle. J Physiol 569:467-473

123. Lavine KJ, Sierra OL (2017) Skeletal muscle inflammation and atrophy in heart failure. Heart Fail Rev 22:179-189

124. Mancini DM, Coyle E, Coggan A et al (1989) Contribution of intrinsic skeletal muscle changes to 31P NMR skeletal muscle metabolic abnormalities in patients with chronic heart failure. Circulation 80:1338-1346

125. Hornby B, McClellan R, Buckley L, Carson K, Gooding T, Vernon HJ (2019) Functional exercise capacity, strength, balance and motion reaction time in Barth syndrome. Orphanet J Rare Dis 14(1):37

126. Kushmerick MJ, Moerland TS, Wiseman RW (1992) Mammalian skeletal muscle fibers distinguished by contents of phosphocreatine, ATP, and Pi. Proc Natl Acad Sci U S A 89:7521-7525

127. Takahashi H, Kuno SY, Katsuta S, Shimojo H, Masuda K, Yoshioka H, Anno I, Itai Y (1996) Relationships between fiber composition and NMR measurements in human skeletal muscle. NMR Biomed 9:8-12

128. Cade WT, Spencer CT, Reeds DN, Waggoner AD, O'Connor R, Maisenbacher M, Crowley JR, Byrne BJ, Peterson LR (2013) Substrate metabolism during basal and hyperinsulinemic conditions in adolescents and young-adults with Barth syndrome. J Inherit Metab Dis 36:91-101

129. Kemp GJ, Ahmad RE, Nicolay K, Prompers JJ (2015) Quantification of skeletal muscle mitochondrial function by 31P magnetic resonance spectroscopy techniques: a quantitative review. Acta Physiol 213:107-144

130. Wasserman K (1987) Determinants and detection of anaerobic threshold and consequences of exercise above it. Circulation 76: VI29-VI39 
131. Gonzalvez F, D’Aurelio M, Boutant M, Moustapha A, Puech JP, Landes T, Arnauné-Pelloquin L, Vial G, Taleux N, Slomianny C, Wanders RJ, Houtkooper RH, Bellenguer P, Møller IM, Gottlieb E, Vaz FM, Manfredi G, Petit PX (2013) Barth syndrome: cellular compensation of mitochondrial dysfunction and apoptosis inhibition due to changes in cardiolipin remodeling linked to tafazzin (TAZ) gene mutation. Biochim Biophys Acta 1832:1194-1206

132. Xu Y, Phoon CK, Berno B, D'Souza K, Hoedt E, Zhang G, Neubert TA, Epand RM, Ren M, Schlame M (2016) Loss of protein association causes cardiolipin degradation in Barth syndrome. Nat Chem Biol 12:641-647

133. Barth PG, Scholte HR, Berden JA, Van der Klei-Van Moorsel JM, Luyt-Houwen IE, Van' t Veer-Korthof ET, Van der Harten JJ, Sobotka-Plojhar MA (1983) An X-linked mitochondrial disease affecting cardiac muscle, skeletal muscle and neutrophil leucocytes. J Neurol Sci 62:327-355

134. Coman D, Yaplito-Lee J, Boneh A (2008) New indications and controversies in arginine therapy. Clin Nutr 27:489-496

135. Rigaud C, Lebre AS, Touraine R, Beaupain B, Ottolenghi C, Chabli A, Ansquer H, Ozsahin H, Di Filippo S, De Lonlay P, Borm B, Rivier F, Vaillant MC, Mathieu-Dramard M, Goldenberg A, Viot G, Charron P, Rio M, Bonnet D, Donadieu J (2013) Natural history of Barth syndrome: a national cohort study of 22 patients. Orphanet J Rare Dis 8:70

136. Yen TY, Hwu WL, Chien YH, Wu MH, Lin MT, Tsao LY, Hsieh WS, Lee NC (2008) Acute metabolic decompensation and sudden death in Barth syndrome: report of a family and a literature review. Eur J Pediatr 167:941-944

137. Spencer CT, Byrne BJ, Gewitz MH, Wechsler SB, Kao AC, Gerstenfeld EP, Merliss AD, Carboni MP, Bryant RM (2005) Ventricular arrhythmia in the X-linked cardiomyopathy Barth syndrome. Pediatr Cardiol 26:632-637

138. Jefferies JL, Morales DL (2012) Mechanical circulatory support in children: bridge to transplant versus recovery. Curr Heart Fail Rep 9:236-243

139. Fraser CD Jr, Jaquiss RD, Rosenthal DN, Humpl T, Canter CE, Blackstone EH, Naftel DC, Ichord RN, Bomgaars L, Tweddell JS, Massicotte MP, Turrentine MW, Cohen GQ, Devaney EJ, Pearce FB, Carberry KE, Kroslowitz R, Almond CS Berlin Heart Study (2012) Prospective trial of a pediatric ventricular assist device. N Engl J Med 367:532-541

140. Dedieu N, Giardini A, Steward CG, Fenton M, Karimova A, Hsia TY, Burch M (2013) Successful mechanical circulatory support for 251 days in a child with intermittent severe neutropenia due to Barth syndrome. Pediatr Transplant 17:E46-E49

141. Mangat J, Lunnon-Wood T, Rees P, Elliott M, Burch M (2007) Successful cardiac transplantation in Barth syndrome-singlecenter experience of four patients. Pediatr Transplant 11:327-331

142. Schnepp BC, Clark KR, Klemanski DL, Pacak CA, Johnson PR (2003) Genetic fate of recombinant adenoassociated virus vector genomes in muscle. J Virol 77:3495-3504

143. Huang Y, Powers C, Moore V, Schafer C, Ren M, Phoon CKL, James JF, Glukhov AV, Javadov S, Vaz FM, Jefferies JL, Strauss AW, Khuchua Z (2017) The PPAR pan-agonist bezafibrate ameliorates cardiomyopathy in a mouse model of Barth syndrome. Orphanet J Rare Dis 12:49-64

144. He Q, Harris N, Ren J, Han X (2014) Mitochondria-targeted antioxidant prevents cardiac dysfunction induced by tafazzin gene knockdown in cardiac myocytes. Oxidative Med Cell Longev 2014:654198

145. Dai DF, Hsieh EJ, Chen T, Menendez LG, Basisty NB, Tsai L, Beyer RP, Crispin DA, Shulman NJ, Szeto RH, Tian R, MacCoss MJ, Rabinovitch PS (2013) Global proteomics and pathway analysis of pressure overload-induced heart failure and its attenuation by mitochondrial-targeted peptides. Circ Heart Fail 6:1067-1076
146. Szeto HH, Liu S, Soong Y, Wu D, Darrah SF, Cheng FY, Zhao Z, Ganger M, Tow CY, Seshan SV (2011) Mitochondria-targeted peptide accelerates ATP recovery and reduces ischemic kidney injury. J Am Soc Nephrol 22:1041-1052

147. Talbert EE, Smuder AJ, Min K, Kwon OS, Szeto HH, Powers SK (2013) Immobilization-induced activation of key proteolytic systems in skeletal muscles is prevented by a mitochondria-targeted antioxidant. J Appl Physiol 115:529-538

148. Yang L, Zhao K, Calingasan NY, Luo G, Szeto HH, Beal ME (2009) Mitochondria targeted peptides protect against 1-methy14-phenyl-1,2,3,6-tetrahydropyridine neurotoxicity. Antioxid Redox Signal 11:2095-2104

149. Brown DA, Hale SL, Baines CP, del Rio CL, Hamlin RL, Yueyama Y, Kijtawomrat A, Yeh ST, Frasier CR, Stewart LM, Moukdar F, Shaikh SR, Fisher-Wellman KH, Neufer PD, Kloner RA (2014) Reduction of early reperfusion injury with the mitochondria-targeting peptide bendavia. J Cardiovasc Pharmacol Then 19:121-132

150. Allen ME, Pennington ER, Perry JB, Dadoo S, Makrecka-Kuka M, Dambrova M, Moukdar F, Patel HD, Han X, Kidd GK, Benson EK, Raisch TB, Poelzing S, Brown DA, Shaikh SR (2020) Mitochondrial cristae networks in the post-ischemic heart: mitigation of ultrastructural and functional derangements with a cardiolipin-binding peptide. Nat Commun Biol 3(389). https://doi. org/10.1038/s42003-020-1101-3

151. Birk AV, Liu S, Soong Y, Mills W, Singh P, Warren JD, Seshan SV, Pardee JD, Szeto HH (2013) The mitochondrial-targeted compound SS-31 reenergizes ischemic mitochondria by interacting with cardiolipin. J Am Soc Nephrol 24:1250-1261

152. Sabbah HN, Gupta RC, Kohli S, Wang M, Hachem S, Zhang K (2016) Chronic therapy with elamipretide (MTP-131), a novel mitochondria-targeting peptide, improves left ventricular and mitochondrial function in dogs with advanced heart failure. Circ Heart Fail 9:e002206

153. Chatfield KC, Sparagna GC, Chau S, Phillips FK, Ambardekar AV, Aftab M, Mitchell MB, Sucharov CC, Miyamoto SD, Stauffer BL (2019) Elamipretide improves mitochondrial function in the failing human heart. JACC 4(2):147-157

154. Frohman MA (2015) Role of mitochondrial lipids in guiding fission and fusion. Mol Med 93:263-269

155. Joshi AS, Thompson MN, Fei N, Huttemann M, Greenberg ML (2012) Cardiolipin and mitochondrial phosphatidylethanolamine have overlapping functions in mitochondrial fusion in Saccharomyces cerevisiae. J Biol Chem 287:17589-17597

156. Sabbah HN, Gupta RC, Singh-Gupta V, Zhang K, Lanfear DE (2018) Abnormalities of mitochondrial dynamics in the failing heart: normalization following long-term therapy with elamipretide. Cardiovasc Drugs Ther 32:319-328

157. Givvimani S, Pushpakumar S, Veeranki S, Tyagi SC (2014) Dysregulation of Mfn2 and Drp-1 proteins in heart failure. Can J Physiol Pharmacol 92:583-591

158. Chen L, Gong Q, Stice JP, Knowlton AA (2009) Mitochondrial OPA1, apoptosis, and heart failure. Cardiovasc Res 84:91-99

159. Sharov VG, Sabbah HN, Shimoyama H, Goussev AV, Lesch M, Goldstein S (1996) Evidence of cardiocyte apoptosis in myocardium of dogs with chronic heart failure. Am J Pathol 148:141-149

160. Sabbah HN, Sharov VG (1998) Apoptosis in heart failure. Prog Cardiovasc Dis 40:549-562

161. Shires SE, Gustafsson AB (2018) Regulating renewable energy: connecting AMPKalpha2 to PINK1/Parkin-mediated mitophagy in the heart. Circ Res 122:649-651

162. Song M, Mihara K, Chen Y, Scorrano L, Dorn GW 2nd (2015) Mitochondrial fission and fusion factors reciprocally orchestrate mitophagic culling in mouse hearts and cultured fibroblasts. Cell Metab 21:273-286 
163. Sharov VG, Goussev A, Lesch M, Goldstein S, Sabbah HN (1998) Abnormal mitochondrial function in myocardium of dogs with chronic heart failure. J Mol Cell Cardiol 30:1757-1762

164. Sharov VG, Todor AV, Silverman N, Goldstein S, Sabbah HN (2000) Abnormal mitochondrial respiration in failed human myocardium. J Mol Cell Cardiol 32:2361-2367

165. Song M, Chen Y, Gong G, Murphy E, Rabinovitch PS, Dorn GW 2nd (2014) Super-suppression of mitochondrial reactive oxygen species signaling impairs compensatory autophagy in primary mitophagic cardiomyopathy. Circ Res 115:348-353

166. Sharov VG, Todor A, Khanal S, Imai M, Sabbah HN (2007) Cyclosporine A attenuates mitochondrial permeability transition and improves mitochondrial respiratory function in cardiomyocytes isolated from dogs with heart failure. J Mol Cell Cardiol 42:150-158

167. Sharov VG, Todor AV, Imai M, Sabbah HN (2005) Inhibition of mitochondrial permeability transition pores by cyclosporine A improves cytochrome $\mathrm{C}$ oxidase function and increases rate of ATP synthesis in failing cardiomyocytes. Heart Fail Rev 10:305-310

168. Gellerich FN, Khuchua ZA, Kuznetsov AV (1993) Influence of the mitochondrial outer membrane and the binding of creatine kinase to the mitochondrial inner membrane on the compartmentation of adenine nucleotides in the intermembrane space of rat heart mitochondria. Biochim Biophys Acta 1140:327-334

169. Halestrap AP, Pasdois P (2009) The role of the mitochondrial permeability transition pore in heart disease. Biochim Biophys Acta 1787:1402-1415

170. Whelan RS, Kaplinskiy V, Kitsis RN (2010) Cell death in the pathogenesis of heart disease: mechanisms and significance. Annu Rev Physiol 72:19-44

171. Huttemann M, Pecina P, Rainbolt $M$ et al (2011) The multiple functions of cytochrome $\mathrm{c}$ and their regulation in life and death decisions of the mammalian cell: from respiration to apoptosis. Mitochondrion 11:369-381

172. Ikeda Y, Shirakabe A, Brady C, Zablocki D, Ohishi M, Sadoshima J (2015) Molecular mechanisms mediating mitochondrial dynamics and mitophagy and their functional roles in the cardiovascular system. J Mol Cell Cardiol 78:116-122

173. Korge P, Ping P, Weiss JN (2008) Reactive oxygen species production in energized cardiac mitochondria during hypoxia/reoxygenation: modulation by nitric oxide. Circ Res 103:873-880

174. Paradies G, Petrosillo G, Paradies V, Ruggiero FM (2009) Role of cardiolipin peroxidation and $\mathrm{Ca} 2+$ in mitochondrial dysfunction and disease. Cell Calcium 45:643-650

175. Stadtman ER (2006) Protein oxidation and aging. Free Radic Res 40:1250-1258

176. Maynard S, de Souza-Pinto NC, Scheibye-Knudsen M, Bohr VA (2010) Mitochondrial base excision repair assays. Methods 51: 416-425
177. Andreadou I, Iliodromitis EK, Farmakis D, Kremastinos DT (2009) To prevent, protect and save the ischemic heart: antioxidants revisited. Expert Opin Ther Targets 13:945-956

178. Goh KY, Qu J, Hong H et al (2016) Impaired mitochondrial network excitability in failing Guinea-pig cardiomyocytes. Cardiovasc Res 109:79-89

179. Ide T, Tsutsui H, Hayashidani S et al (2001) Mitochondrial DNA damage and dysfunction associated with oxidative stress in failing hearts after myocardial infarction. Circ Res 88:529-535

180. Ide T, Tsutsui H, Kinugawa $\mathrm{S}$ et al (2000) Direct evidence for increased hydroxyl radicals originating from superoxide in the failing myocardium. Circ Res 86:152-157

181. Daubert MA, Yow E, Dunn G, Marchev S, Barnhart H, Douglas PS, O'Connor C, Goldstein MDS, Udelson JE, Sabbah HN (2017) Novel mitochondria-targeting peptide in heart failure treatment. A randomized, placebo-controlled trial of elamipretide. Circulation 10(12):e004389

182. Eirin A, Ebrahimi B, Hyo Kwon S, Fiala JA, Williams BJ, Woollard JR, He Q, Gupta RC, Sabbah HN, Prakash YS, Textor SC, Lerman A, Lerman LO (2016) Restoration of mitochondrial cardiolipin attenuates cardiac damage in swine renovascular hypertension. J Am Heart Assoc 5(6):e003118

183. Gupta RC, Singh-Gupta V, Zhang K, Sabbah HN, Gupta RC, Singh-Gupta V, Zhang K (2019) Effects of elamipretide on skeletal muscle in dogs with heart failure. ESC Heart Failure 6:328335

184. Karaa A, Haas R, Goldstein A, Vockley J, Weaver DW, Cohen BH (2018) Randomized dose-escalation trial of elamipretide in adults with primary mitochondrial myopathy. Neurology 90: e1212-e1221

185. Thompson WR, Manuel, Aiudi A, Jones JJ, Carr J, Hornby B, Vernon HJ (2020) Elamipretide in patients with Barth syndrome: a randomized, double-blind, placebo-controlled clinical trial followed by 36-week open-label extension. Presented at: The American College of Cardiology Scientific Session 2020. March 28-30, Chicago

186. Thompson WR, Manuel, Aiudi A, Jones JJ, Carr J, Hornby B, Vernon HJ (2020) Elamipretide in patients with Barth syndrome: a randomized, double-blind, placebo-controlled clinical trial followed by a 36-week open-label extension. Presented at: 2020 Barth Syndrome Foundation Scientific and Medical Symposium. July 20-26, Clearwater

Publisher's note Springer Nature remains neutral with regard to jurisdictional claims in published maps and institutional affiliations. 